\title{
Interest Rate Swap Market Complexity and Its Risk Management Implications
}

\author{
Steve Y. Yang $\mathbb{D}^{1}$ and Esen Onur ${ }^{2}$ \\ ${ }^{1}$ School of Business, Stevens Institute of Technology, 1 Castle Point on Hudson, Hoboken, NJ 03070, USA \\ ${ }^{2}$ Office of Chief Economist, Commodity Futures Trading Commission, 1551 Lafayette Center, Washington, DC 20581, USA \\ Correspondence should be addressed to Steve Y. Yang; steve.yang@stevens.edu
}

Received 20 June 2018; Accepted 6 September 2018; Published 24 October 2018

Academic Editor: Dimitri Volchenkov

Copyright ( 2018 Steve Y. Yang and Esen Onur. This is an open access article distributed under the Creative Commons Attribution License, which permits unrestricted use, distribution, and reproduction in any medium, provided the original work is properly cited.

\begin{abstract}
The primary objective of this paper is to study the post Dodd-Frank network structure of the interest rate swap market and propose a set of effective complexity measures to understand how the swap users respond to market risks. We use a unique swap dataset extracted from the swap data repositories (SDRs) to examine the network structure properties and market participants' risk management behaviors. We find (a) the interest rate swap market follows a scale-free network where the power-law exponent is less than 2, which indicates that few of its important entities have a significant number of contracts within their subsidiaries (a.k.a. interaffiliated swap contracts); (b) swap rate volatility Granger-causes swap users to increase their risk sharing intensity at entity level, but market participants do not change their risk management strategies in general; (c) there is a significant contemporaneous correlation between the swap rate volatility and the underlying interest rate futures volatility. However, interest rate swap volatility does not cause the underlying interest rate futures volatility and vice versa. These findings provide the market regulators and swap users a better understanding of interest rate swap market participants' risk management behaviors, and it also provides a method to monitor the swap market risk sharing dynamics.
\end{abstract}

\section{Introduction and Background}

Since the 2008-09 financial crisis, there are multitudes of new policies being proposed and successfully implemented to improve resiliency of the financial system in response to extreme events. The Dodd-Frank Act and the Basel II are among the most notable examples. A main component of the new policies put in place had been with respect to the swaps market, which, before the financial reforms, was decentralized and opaque in terms of understanding who had exposure to whom and the magnitude of their exposures. A few examples of the financial reforms that have changed the topology of the financial system, and especially the swaps market, were requirements following the Dodd-Frank Act, namely real-time reporting of swap transactions, clearing mandate applicable to certain, swaps and the made available to trade (MAT) mandate which required certain swaps to be traded on Swap Execution Facilities (SEFs). While all these changes were done in the hopes of preventing another financial crisis, they have definitely changed how swaps are traded and how information about swaps are disseminated in the market. A key question now is how is the swaps market shaped after all the structural changes?

Prior to the implementation of Dodd-Frank Act, swap trading was largely decentralized and over-the-counter (OTC) since its inception in the early 1980s. The terms and language of individual swap contracts, which were sponsored by the International Swaps and Derivatives Association (ISDA), allowed market participants to converge to a common set of market practices and standards. However, buyers and sellers of the swap contracts bore pecuniary and time costs when searching for counterparties and negotiating contract terms [1]. A party would enter a swap typically for one of the two reasons, as a hedge for another position or to speculate on the future value of the underlying asset. Swaps are generally categorized into five different asset classes (based on the general underlyings they are written on): interest rate swaps, credit default swaps, foreign exchange 
swaps, commodity swaps, and equity swaps. Most swaps are entered into with dealers, who then seek to limit their exposure to the underlier risk by entering into offsetting swaps with other counterparties. In addition to swap dealers, major market participants include financial institutions and other corporations, international organizations, government-sponsored enterprises, corporate bond and mortgage-backed securities dealers, and hedge funds. According to the Bank of International Settlements (BIS), notional amounts of all types of OTC contracts stood at \$683.7 trillion at the end of June 2008 (BIS, 2008). This number has reduced to $\$ 544$ trillion by the end of June 2016 , and $75 \%$ of these derivative contracts were cleared by central clearing parties (CCPs) (BIS, 2016). This signals a drastic structural change in the largest financial market in the world.

A major change to interest rate swap (IRS) trading as a result of Dodd-Frank was the introduction of SEFs which features a multidealer request for quote (RFQ) functionality as well as an open limit order book (LOB). Since early February 2014, the Commodity Futures Trading Commission (CFTC) has mandated that all trades in eligible swap contracts that involve US persons (besides US-registered swap dealers and major participants, the definition of a US person also includes foreign entities that carry guarantees from a U.S. person, e.g., the foreign branch of a US dealer, and also any entities with personnel on US soil which is substantially involved in arranging, negotiating, or executing a transaction. On October 11, 2016, the CFTC redefined the terms "US Person" and "Foreign Consolidated Subsidiary" to align more closely with the definitions in the final CFTC cross-border margin rules for uncleared swaps (cross-border margin rules). See https://www.gpo.gov/fdsys/pkg/FR-2016$10-18 /$ pdf/2016-24905.pdf) must take place on a SEF. This mandate captured a wide range of interest rate swap contracts of various currencies and maturities as well as several credit default swaps (CDS) indices. As a result of the new market design, the swap trading should become more centralized and more pretrade transparent, and the transparency of the market and competition among swap dealers should have brought many benefits to the world's largest financial market (BIS 2016). A number of studies have emerged aiming to bring better understanding of the benefits and impact of the swap market structural changes post Dodd-Frank Act [2-4]. Our study is aimed at understanding the post Dodd-Frank swap market structure and proposing effective measures to quantify the market risk management characteristics.

In this paper, we focus on the interest rate swap market (referred to as "IRS" or "swap" in the rest of the paper) and aim to understand the dynamics of the counterparty risk sharing mechanism under the new market design. In particular, we examine the network structure of the interest rate swap market and introduce a set of complexity measures to understand the dynamics of the interest rate swap contract flows among different participants of the market. These complexity measures are introduced to capture the counterparty exposures both at global strategic level and at local entity level. We, then, use these measures to understand how swap users react to the underlying and the swap market volatility.
We use a unique dataset extracted from the swap data repositories (SDRs) which reports the details of transactions among the swap users. This regulatory dataset, accessed by the Commodity Futures Trading Commission, gives us the opportunity to examine the counterparty risk exposures on a daily basis and understand the characteristics of connectedness and concentration of the interest rate swap market. To the best of our knowledge, this is the first paper that focuses on the dynamics of counterparty risk sharing within the interest rate swap market in the U.S. (a report published by the European Central Bank [5] analyzes the interest rate swap market in the E.U.). We focus on interest rate swaps because of their importance for the global financial system and the size of the risk transfer they enable on a daily basis.

We show that the interest rate swap market follows a scale-free network structure where few big entities form the core and all other entities have relatively low connectivity, shaping a coreperipheral network structure. This finding indicates that the IRS network is very similar to the CDS market which implies that total credit risk exposure is fairly concentrated [6,7]. Furthermore, we also find that these large swap entities generate significant swap positions among their subsidiaries. Activities of the few powerful nodes induce a large portion of the complexity of the entire network. We document that swap market volatility Granger-causes swap market complexity to change which can be interpreted as the change of counterparty diversification at global level and risk sharing intensity at local level. When we further decompose the complexity, we find that the swap market volatility does not significantly change the global diversification among the market participants, but it largely causes the contract flow intensity change at entity level. This implies that swap market participants, especially swap dealers, do not change their risk management strategies in response to changes in the swap market volatility. Furthermore, we find that swap market volatility is only contemporaneously correlated with the underlying interest rate risk. The interest rate risk measured by the Eurodollar futures (the interest rate swaps examined in our paper are based on a specific interest rate, LIBOR, the London Interbank Offered Rate. However, swaps are not the only derivative that is based on this interest rate and it is reasonable to assume that two markets based on the same underlier can be quite correlated. Another widely used derivative based on LIBOR is The Eurodollar futures traded on the Chicago Mercantile Exchange (CME). Following Minton [8], we use the Eurodollar futures to represent the LIBOR interest rate risk) volatility does not Granger-cause swap rate volatility, and likewise, the Eurodollar futures does not Granger-cause the swap market volatility. These findings provide regulators and swap market participants a better understanding of the risk-sharing dynamics in the interest rate swap market. Proper interpretation of swap market complexity would allow regulators to better understand the role of systemically important entities and the implications of their risk management behaviors to the entire system. At the same time, it will allow swap users to understand risk hedging with a holistic perspective.

The remainder of the paper is structured as follows. Section 2 reviews related work in the area of financial networks 
and swap market studies in particular. Section 3 presents the complexity measure and the data we use to analyze the IRS market. The empirical analysis and modeling results are then presented and discussed in Section 4, and we conclude the findings and implications in Section 5.

\section{Literature Review}

The first strand of literature this paper relates to is on the study of risk management role of the interest rate swaps. These studies focus on the role of interest rate swap and how interest rate risks are managed by the swap users. In Cossin and Pirotte [9], the authors acquire a proprietary swaps transaction dataset of interest rate and cross currency swaps from a medium-sized European bank and analyze the presence of credit risk in the pricing of swap deals. In Balsam and Kim [10], the researchers analyze the effect of the usage of interest rate swaps on certain characteristics of the firms that use them and find that firms that engage in interest rate swaps have lower cash flow variance than firms that do not, suggesting hedging as the potential reason for using these kinds of swaps. In a similar vein, Li and Mao [11] investigate the kinds of firms that take the fixed or floating leg of an interest rate swap and find that fixed-rate swap payers generally have lower credit ratings, higher leverage ratios, higher percentages of long-term floating-rate loans, and are more likely to use bank loans than floating-rate swap payers. Harper and Wingender [12] analyze the reason for the growth in the interest rate swap market in the 1990s and find strong support for the theory suggesting that one of the benefits of interest rate swaps is a reduction in agency costs. To understand the risk implications, Azad et al. [13] try to link the volatility of interest rate swap markets to the macroeconomic risk in the UK and US. They find a strong relationship between uncertainties of macroeconomic fundamentals and the fluctuation in swap market volatility and suggest that that policy makers should use low-frequency volatility in order to examine market responses to key macroeconomic policies. Byun and Chang [14] further examine whether the interest rate market compensates for volatility risk. They find that there is negative compensation for volatility risk premiums similar to the equity or currency markets in the short term while there is a possibility that the volatility risk premium in the interest rate market can be different from those in other asset markets in the long term.

A number of studies have also focused on the swaps market and especially the effects of the financial reforms on swap market structural changes. Recently, a number of studies have emerged analyzing these effects. Fulop and Lescourret [3] study impact on liquidity of the contract standardization and the reporting of aggregate weekly posttrade in a singlename CDS market. They find that the standardization of CDS contracts improved liquidity, while the posttrade data disclosure improved the liquidity only for a subset of CDS contracts. Loon and Zhong [15] study the effects of DoddFrank focusing on the two key provision of the Act: centralized clearing and posttrade reporting. They analyze the index CDS market and the impact of public reporting of transactions and find that liquidity in the index CDS market has improved as a result. Benos et al. [2] analyze the impact of the introduction of Swap Execution Facilities (SEFs) into the marketplace in the US and the requirement that certain swaps have to be traded on these facilities. They combine the publicly reported interest rate swaps data from SDRs with a private dataset they have acquired from a clearing organization and analyze the effect of these changes in the IRS market. Their main findings indicate that these changes in the market structure have improved liquidity and cut execution costs for end-users. The authors also find that the biggest improvements in liquidity can be attributed to the introduction of SEFs. In contrast to the findings of Benos et al. [2], Kaya [16] finds that after the requirement that certain swaps need to be cleared, spreads on credit default swaps (CDSs) written on nonfinancial firms widen. They claim that if the cost of central clearing gets passed on to end-users, they might not be able to hedge their exposures due to increased costs. Other studies have focused on the change in trading methods available after financial regulations. Collin-Dufresne et al. [17] use swap data reported on SDRs to analyze the differences across dealer-to-client (D2C) and dealer-to-dealer (D2D) SEFs in the index CDS market. The researchers differentiate between SEFs that are known to be D2C and D2D exchanges and find transaction costs and price impacts to be larger for D2C trades.

Finally, our study is closely related to a group of studies whose focus is on the topological structures of the counterparty risk implications. Boss et al. [18], Iori et al. [19], and Cont et al. [20] investigated the interbank market in Australia, Italy, and Brazil, respectively. They discovered similar network features of the banking system in those countries: (1) sparsity and short average distance among nodes; (2) heterogeneous nodes' degree which follows power-law distribution; (3) small clustering; and (4) small-world properties. Second, some recent studies expanded the scope to the total network, including overnight transactions, shortterm loans, and long-term loans in the aggregate. In addition, the total network shows that the nodes with higher degree tend to have larger exposures compared with lower degree nodes [21]. Boss et al. [18] and Markose et al. [6] study the CDS market network structures during the financial crisis and conclude that the dominance of a few big players in the chains of insurance and reinsurance for CDS credit risk mitigation for banks' assets has led to the idea of too interconnected to fail (TITF), resulting, as in the case of AIG, in a tax payer bailout. They propose a super-spreader tax based on eigenvector centrality of the banks which can mitigate potential socialized losses that would trigger systemic risks. Peltonen et al. [7] study the CDS structural characteristics and find that the CDS spread volatility and market beta are statistically significantly related to structural characteristics of the CDS market. This finding is consistent with the theoretical literature on the use of CDS. Acemoglu et al. [22] introduce a notion of distance over the financial network that captures the propensity of a bank to be in distress when another bank is in distress. Using their measure, they can identify the institutions generating the maximal number of defaults following a shock to this particular institution, i.e., the SIFIs. 


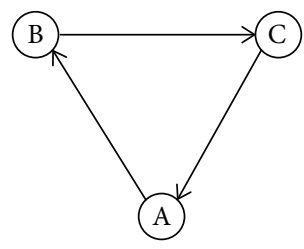

(a)

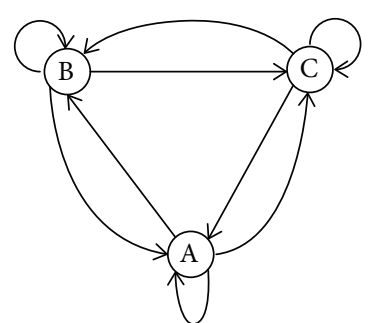

(b)

Figure 1: An unweighted network (a) with 3 nodes, 3 flows, a connectivity of 1 flow per node, and 3 roles and (b) with 3 nodes, 9 flows, a connectivity of 3 flows per node, and 1 role.

\section{Methodology and Data}

Networks with high complexity are characterized by both high vertex-vertex connectedness and small vertex-vertex separation (the small-world concept of Watts and Strogatz [23]). Therefore, it seems logical to use both quantities in characterizing network complexity. Furthermore, in many cases, there is a notion of "magnitude" related to a vertexvertex connection which may further modify the notion of connectedness. The typical example would be traffic flows among a set of cities. The connectedness of these cities will not only be represented by whether there are roads connecting any pair of the cities but also how much traffic flows through those connected cities. Similarly in the context of measuring the connectedness of the swap market, it matters not only that a swap contract exists between any pair of swap users but also the notional value of the swap contracts. In this section, we will introduce a set of complexity measures and then use a few stylized swap network examples to illustrate the effectiveness of these measures to develop an intuition for applications.

In this paper, we define an interest rate swap network using the swap contract reference entities as vertices $\mathbf{V}$, contracts between two reference entities as edges $\mathbf{E}$, and the notional values of the contracts as weights of the corresponding edges $\mathbf{c}=c(i, j), i, j \in \mathbf{V}$. By market convention for interest rate swaps, the counterparty paying the fixed rate is the "payer"-receiving the floating rate, and the counterparty receiving the fixed rate is the "receiver"-paying the floating rate. We therefore model the market as a direct network in which each interest rate swap contract has a direction pointing from "payer" to "receiver". For example, we define any entity (vertex) pair $i$ and $j$ and the contractual relationship between $i$ and $j$ as $T_{i j}=c(i, j)$, which denotes a directed edge from vertex $i$ to vertex $j$.

3.1. Complexity Measure of Swap Networks. Complexity is a key measure in the methodology we propose here. We adopt a few network complexity measures which are originally introduced by theoretical ecologists. Ulanowlcz and Norden [24] introduced the degree of network complexity quantified by the concepts of connectivity and the number of roles of a network. These two concepts are first defined for an unweighted network and then extended to a weighted one in this section.
Let $N, F$, and $C$ be the number of nodes, the number of edges, and the connectivity of a network, respectively. Connectivity can then be defined as $C=F / N$, the average number of flows per node in the network. It conceptually quantifies the fraction of possible flows that are realized; this measure has dimension flows per node squared. In Figure 1, it is not difficult to count the number of nodes and the number of flows, and then we can use the definition of connectivity to calculate that the network in (a) has a connectivity of 1 per node and the network in (b) has a connectivity of 3 .

In addition, the number of roles, which was first introduced by Ulanowlcz and Norden [24], is defined as the ratio of the connectivity of a network to the number of nodes in the network. It can be loosely conceptualized as a function which quantifies a group of vertices that takes its inputs from one source and passes them to a single destination. We, therefore, define $R=N / C=N^{2} / F$ as the number of roles in a network. As an example, we examine the two networks in Figure 1 again. The network in (a) has 3 roles in that all three nodes play three different roles in terms of moving flow from the source to the destination. However, the network in (b) has only 1 role in that the compartments are indistinguishable with respect to where they receive or channel their flows, and as a group they play only one role.

Ulanowicz [25] extends these complexity measures into a weighted network. Among various weighting schemes, the weighted geometric mean is used and is proven to be the only one logically consistent with the unweighted network to extend complexity measures into the weighted network. Let $T_{i j}$ denote the magnitude of a flow from a node $i$ to a node $j$. Let $T_{i}=\sum_{j} T_{i j}$ denote the total magnitude of outflows of a node $i, T_{. j}=\sum_{j} T_{i j}$ denote the total magnitude of inflows of a node $j$, and $T_{. .}=\sum_{i, j} T_{i j}$ denote the total magnitude of flows within a network. $T_{\text {.. }}$ is known as the total system throughput (TST). Let $T_{i}$. and $T_{. i}$ be the output and input throughputs of node $i$, respectively. Hence, we arrive at the following set of effective measures for weighted networks.

$$
C=\prod_{i, j}\left(\frac{T_{i j}^{2}}{T_{i \cdot} T_{. j}}\right)^{-(1 / 2) \cdot\left(T_{i j} / T . .\right)}
$$




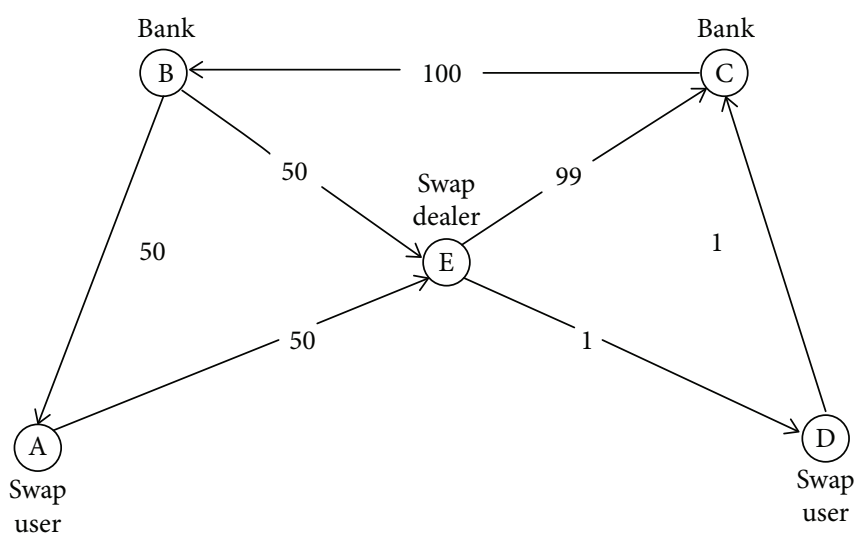

(a) A directed weighted network example

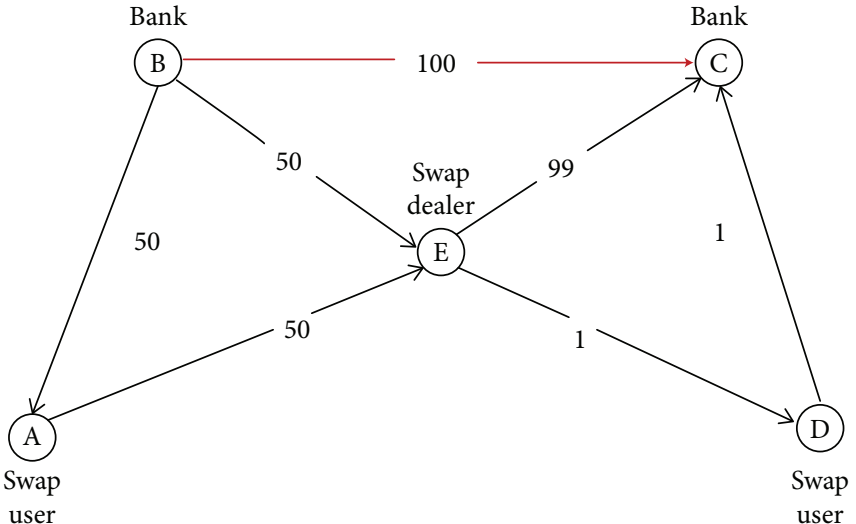

(b) A directed weighted network example with directional change between Band C

Figure 2: A weighted network with 5 swap users. A and D representing two firms, B and C representing two banks, and E representing a swap dealer. Note that the contacts (weight of the edges) are all with the unit of millions of U.S. dollars.

is effective connectivity; it considers branching and condensing structures where the input and output connectivity are unequal.

$$
F=\prod_{i, j}\left(\frac{T_{i j}}{T . .}\right)^{-\left(T_{i j} / T . .\right)}
$$

is the effective number of flows; this number approaches the actual number of flows as the flows approach equal size.

$$
N=\frac{F}{C}=\prod_{i j}\left(\frac{T_{. .}^{2}}{T_{i \cdot T_{. i}}}\right)^{(1 / 2) \cdot\left(T_{i j} / T_{. .}\right)}
$$

is the effective number of nodes in the network; it is a weighted mean of the normalized throughput of each node.

$$
R=\frac{N}{C}=\prod_{i j}\left(\frac{T_{i j} T_{. .}}{T_{i \cdot} T_{. j}}\right)^{\left(T_{i j} / T_{. .}\right)}
$$

is the effective number of roles in the network; it measures the degree to which the system has become differentiated into distinct functions or flow divergence.

The interpretation of these measures is further confirmed using information theory (see derivation of these measures in the appendix). When we consider individual contracts as events, we can then use total entropy $(H)$ to measure their capacity to be significant players in a system change or evolution. MacArthur [26] applied this well-known Shannon's information measure [27] to the flows in an ecosystem network as an important tool to define the system diversity and stability (see (5)). Following Rutledge et al. [28], we have the following equivalence in measuring complexity of a flow network in (5) and (6). AMI measures how orderly and coherently the flows are connected, while $H_{C}$ measures the intensity or potential in the network. MacArthur's index is equivalent to the logarithm of the number of flows in the weighted network. We, therefore, conclude that $A M I$ or $\log$ $(R)$ measures diversification of a flow network, and the $H_{C}$ or $\log (C)$ quantifies the intensity of flow through individual nodes. While the former provides a complexity measure in a global sense, the latter offers a flow intensity measure at the local node level. The sum of the two is the total complexity measure of a flow network.

$$
\begin{aligned}
H & =-k \sum_{h, j}\left(\frac{T_{h j}}{T_{. .}}\right) \log \left(\frac{T_{h j}}{T_{. .}}\right) \\
& =-k \sum_{h, j}\left(\frac{T_{h j}}{T_{. .}}\right) \log \left(\frac{T_{h j} T_{. .}}{T_{h \cdot T_{. j}}}\right)-k \sum_{h, j}\left(\frac{T_{h j}}{T_{. .}}\right) \log \left(\frac{T_{h j}^{2}}{T_{h \cdot T_{. j}}}\right) \\
& =-k \cdot \log (R)-k \cdot \log (C),
\end{aligned}
$$

$$
\begin{aligned}
\text { MacArthur } & =-k \sum_{h, j}\left(\frac{T_{h j}}{T_{. .}}\right) \log \left(\frac{T_{h j}}{T_{. .}}\right)=-k \cdot \log (F), \\
A M I & =-k \sum_{h, j}\left(\frac{T_{h j}}{T_{. .}}\right) \log \left(\frac{T_{h j} T_{. .}}{T_{h \cdot T_{. j}}}\right)=-k \cdot \log (R), \\
H_{C} & =-k \sum_{h, j}\left(\frac{T_{h j}}{T_{. .}}\right) \log \left(\frac{T_{h j}^{2}}{T_{h \cdot T_{. j}}}\right)=-k \cdot \log (C) .
\end{aligned}
$$

To get an intuitive understanding of these two measures in a weighted network, we take a stylized swap network (see Figure 2) as an example and calculate the corresponding weighted network measures as in Table 1 . If we do not count the weight on the edges, the number of nodes would be 5 and the number of flows would be 7. From these two counts, we can derive the connectivity of the network per node as 1.4, and the number of roles is 3.571 . The connectivity measure 
TABLE 1: Comparison of a weighted vs. an unweighted network.

\begin{tabular}{lcccc}
\hline Network type & Eff. \# of nodes & Eff. \# of flows (MacArthur) & Eff. connectivity $\left(H_{C}\right)$ & Eff. \# of roles $(A I M)$ \\
\hline Unweighted & 5 & 7 & 1.4 & 3.571 \\
Weighed network (a) & 3.925 & 4.859 & 1.238 & 3.171 \\
Weighed network (b) & 2.644 & 4.859 & 1.837 & 1.439 \\
\hline
\end{tabular}

Notes: for the weighted network (a) and (b), the only difference is the flow direction between node B and node C. For the unweighted network, we take the network from Figure 2 and assign a unit flow for all the directed edges.

gives a sense of average flow per node, and the number of roles gives us the notion of the number of different functions for a given set of flows. In the unweighted network, the number of roles is 3.571. However, when we look closely at the weighted network (a) in Figure 2 of the swap users, we find a particularly interesting node-D-which has two contracts with significantly smaller notional values with bank (C) and swap dealer (E). Intuitively, we would recognize that their contribution to the entire network flows should be negligible. From Table 1, we can see that using the weighted measures, we have the effective number of nodes as 3.9 which is close to 4 rather than 5 for the unweighted network. The effective number of flows becomes 4.859 which is close to 5 rather than 7 . In fact, we discount the contribution of node (D) in the weighted network accordingly. As a result, we see the effective number of nodes and flows become more realistic, and the effective connectivity and the number of roles of the weighted network are adjusted accordingly. The connectivity of the weighted network reflects the average effective flow per effective node. While the change of connectivity is not significant, the number of roles has decreased from 3.571 to 3.171. It is a little smaller than the unweighted network. Intuitively, we would recognize that the slightly smaller number of roles is reflective of the discounting function of node (D) of this group of entities.

Furthermore, we compare the two weighted networks in Figures 2(a) and 2(b). The only difference between the two weighted networks is the contract flow direction between node (B) and node (C), and the rest remains the same. In another word, the total complexity measured in MacArthur complexity remains the same, while the change happens between the two components, namely, $A M I$ and $H_{C}$. Essentially, we see a consistent risk shifting from bank (B) to bank (C) in Figure 2(b), while in Figure 2(a), we see risk transferring back from bank (C) to bank (B). From the system perspective, the risk transfer in the entire system is more "concentrated" in network (b) than that in network (a). In another word, the risk transfer in network (a) is more diversified. In network (b), bank (B) is essentially paying a total of $\$ 200$ million fixed lags of the interest rate swaps in aggregate, while bank (C) is receiving the total of \$200 million floating lags of the interest rate swaps. Compared with network (a) where the flows for node (B) and (C) are \$100, the individual flows for these two nodes are doubled as a result. When we examine the effective measures of the two weighted networks, we find that the effective number of total flows remains the same, but the effective number of nodes reduced from 3.925 to 2.644 , which means the weighted throughput of each node has reduced. At the same time, if we examine the network (a) in Figure 2, we see there is a balanced flow for both bank (B) and $(\mathrm{C})$. In this case, the net of the exposure to the interest rate swap contact change is zero, which makes sense in terms of risk hedging. However, at the system level the flow is not as "concentrated" as that in network (b) in Figure 2. It is reflected in the effective number of roles presented in Table 1. Network (b) has the effective number of roles of 1.439 and network (a) has 3.171. It means that network (a) is more diversified than network (a). The reduced number of roles in network (b) and the increased divergence in network (a) are both reasonably reflected in the weighted measure. At the same time, the effective connectivity for the two networks also has changed due to the concentrated flow increase through node (B) and (C). While flows through other nodes remain the same, the geometric mean of the flow of all nodes has changed from 1.238 to 1.837 for network (a) and (b), respectively.

Overall, we can see that the weighted network measures represent the swap network much better. The effective number of roles represents the global diversification, while the effective connectivity represents the local flow intensity at the node level. A high effective number of roles indicates better divergence of risk sharing among all nodes. A high effective connectivity shows high volume of contract flows passing through individual nodes on average. In another word, the effective number of roles gives us a sense of risk diversification at the global level, and the effective connectivity provides an average measure of magnitude of risk positions at entity level.

3.2. Volatility and Complexity Autoregressive Model. Once we have measures to quantify IRS market complexity, we employ vector autoregressive model (VAR) to examine the dynamic interactions and interdependencies between the swap network complexity and market volatility. VAR models explain the endogenous variables solely by their own history, apart from deterministic regressors. In order to test the predictability of these variables, we need to test first the Granger causality relationship between volatility variables and the network complexity defined in Section 3.1. We perform Granger causality analysis for each pair of volatility and complexity variables and discuss the results later.

Vector autoregressive model was introduced as a technique to characterize the joint dynamic behavior of a collection of variables without requiring strong restrictions to identify underlying structural parameters. In our analysis, a VAR system contains a volatility variable and complexity measure. Each variable is expressed as a linear function of $n$ 
lags of itself and the others, plus an error term. Our VAR system takes the following form:

$$
\begin{aligned}
& V_{t}=a+\sum_{i=1}^{p} \alpha_{1 i} V_{t-i}+\sum_{i=1}^{p} \beta_{1 i} C_{t-i}+\epsilon_{1 t}, \\
& C_{t}=b+\sum_{i=1}^{p} \alpha_{2 i} V_{t-i}+\sum_{i=1}^{p} \beta_{2 i} C_{t-i}+\epsilon_{2 t}
\end{aligned}
$$

where $V_{t}$ and $C_{t}$ are the volatility and complexity variables, respectively, $\alpha_{1 i}, \alpha_{2 i}, \beta_{1 i}$, and $\beta_{2 i}$ are the coefficients, and $\epsilon_{1 t}$ and $\epsilon_{2 t}$ are the noise terms.

One important characteristic of a VAR (p)-process is its stability. This means that it generates stationary time series with time invariant means, variances, and covariance structure, given sufficient starting values. Before implementing VAR, all time series need to be tested for stationarity with the Augmented Dickey Fuller (ADF) test. For a given sample of the endogenous variables $V_{t}$ and $C_{t}$ and sufficient presample values, the coefficients of a VAR (p)-process can be estimated efficiently by least squares applied separately to each of the equations. We can then employ impulse response analysis of the VAR model to understand the interactions between the two endogenous variables.

3.3. Interest Rate Swap Data Description. The interest rate swap data used in this paper is the transaction level regulatory data that was made available to the CFTC as a result of the Dodd-Frank Act. We focus on USD denominated fixedfloating interest rate swaps, which are the most liquid type of interest rate swaps in the market. The unique feature of our dataset is that we have information on every trade that is in the CFTC's jurisdiction within our sample period. We also have identifiers for counterparties on both sides of the swap in the form of Legal Entity Identifiers (LEIs), as well as a notional value for each swap contract reported in USD. We also have access to other characteristics of the swap, such as the trade date, and start and end dates of the swap, and entity classification.

Using the information on counterparties to each swap, we focus on alpha swaps. Alpha swaps have information on the initial counterparties that entered into the swap. This allows us to capture the transaction before the clearing process begins, which involves the alpha swap getting terminated and then each counterparty entering into a similar swap facing the clearinghouse (preserving the exposure they acquired through the alpha swap but potentially eliminating counterparty risk). Additionally, we also focus on "arm'slength" transactions, which are transactions between two unrelated counterparties. This allows us to take into account only the price-forming transactions in the market. Examples of some non-price-forming transactions can be trades between two affiliates, compression swaps, or allocation swaps.

The time frame of dataset we use is January 1, 2015 to May 31, 2016. We assign any trade reported on a Saturday to the Friday before and any trade reported on a Sunday to the following Monday. This results in 347 trading days. Table 2 describes the basic transaction statistics.
TABLE 2: Basic statistics on the interest rate swap transaction dataset (from $1 / 1 / 2015$ to $5 / 31 / 2016$ ).

\begin{tabular}{lccc}
\hline $\begin{array}{l}\text { Average daily } \\
\text { notional value } \\
\text { (million USD) }\end{array}$ & $\begin{array}{c}\text { Average notional } \\
\text { of transactions } \\
\text { (million USD) }\end{array}$ & $\begin{array}{c}\text { Number of } \\
\text { distinct } \\
\text { transactions }\end{array}$ & $\begin{array}{c}\text { Number of } \\
\text { unique } \\
\text { counterparties }\end{array}$ \\
\hline 156,671 & 98.62 & 560,911 & 18,574 \\
\hline
\end{tabular}

Notes: this table shows the summary of the swap dataset made available to the US Commodity Futures Trading Commission.

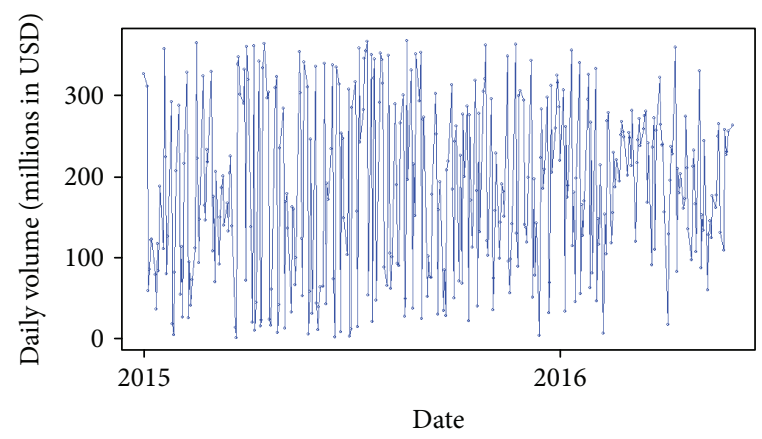

FIgURE 3: Total notional volume of daily transactions of fixed-float interest rate swaps, measured in millions of USD.
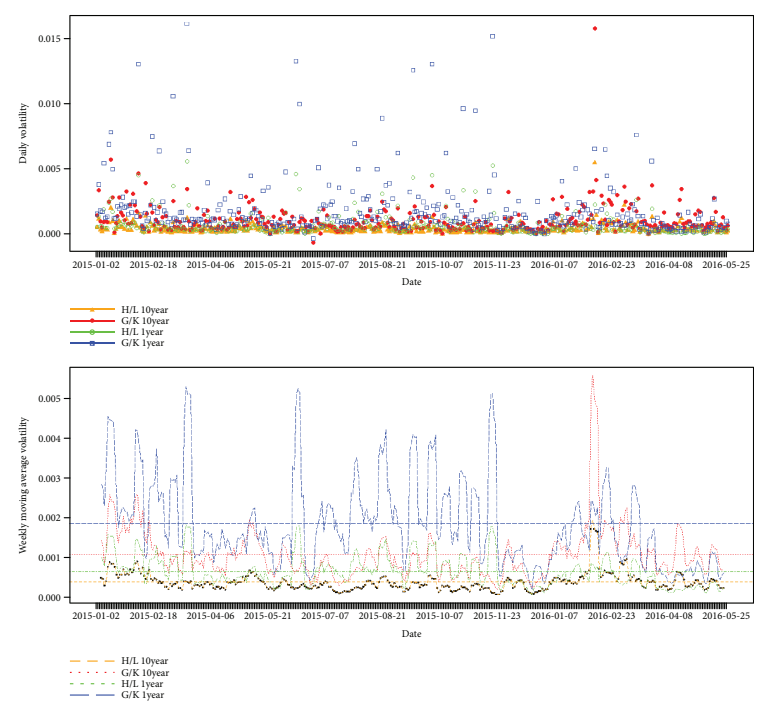

FIgURE 4: The high-low (H/L) volatility estimator for Parkinson (1980) and the Garman and Klass (G/K) volatility estimator of Garman and Klass (1980). The top panel (a) shows daily volatility observations for 1-year and 10-year tenor interest rate swap market, and the bottom panel (b) shows the weekly moving averages of 1-year and 10-year tenor interest rate swaps.

We observe some variety in terms of the daily volume of transactions, measured as the total notional. Figure 3 shows the daily total notional for the dates covered in our sample, measured in millions of USD. We see that there are two days with higher spikes, with a total notional value close to $\$ 700$ billion, but generally the average notional is about $\$ 150$ billion.

In the bottom panel of Figure 4, we show the weekly moving average of the volatility estimates as measured using the 
TABLE 3: Descriptive statistics of variables used.

\begin{tabular}{lcccccc}
\hline Variables & Num. of obs. (days) & Mean & STD & 25th quantile & Median & 75th. quantile \\
\hline Eurodollar futures volatility (H\&L) & 347 & $5.548 e-08$ & $1.044 e-07$ & $8.275 e-09$ & $2.293 e-08$ & $5.852 e-08$ \\
Eurodollar futures volatility (G\&K) & 347 & $5.950 e-08$ & $1.065 e-07$ & $: 1.135 e-08$ & $3.071 e-08$ & $6.138 e-08$ \\
Swap (1-year) rate volatility (H\&L) & 347 & $3.967 e-04$ & $4.120 e-04$ & $1.763 e-04$ & $2.879 e-04$ & $4.824 e-04$ \\
Swap (1-year) rate volatility (G\&K) & 347 & $1.117 e-03$ & $1.165 e-03$ & $5.056 e-04$ & $7.937 e-04$ & $1.371 e-03$ \\
Swap (10-year) rate volatility (H\&L) & 347 & $6.637 e-04$ & $8.031 e-04$ & $2.592 e-04$ & $4.115 e-04$ & $6.781 e-04$ \\
Swap (10-year) rate volatility (G\&K) & 347 & $1.897 e-03$ & $2.321 e-03$ & $7.340 e-04$ & $1.174 e-03$ & $1.956 e-03$ \\
MacArthur complexity & 347 & 8.805 & 0.910 & 8.462 & 8.912 & 9.361 \\
AMI complexity & 347 & 0.3178 & 0.8429 & -0.0233 & 0.5257 & 0.8586 \\
$H_{C}$ complexity & 347 & 8.4874 & 1.3906 & 7.7192 & 8.4763 & 9.1966 \\
\hline
\end{tabular}

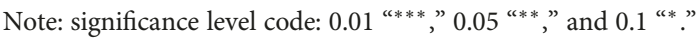

high-low volatility estimator (H/L) of Parkinson (1980) and also using the Garman and Klass (1980) volatility estimator $(\mathrm{G} / \mathrm{K})$. The former uses the daily high and low prices to estimate daily volatility and it follows the form

$$
\widehat{\sigma}_{t}^{2}=\frac{\left(\operatorname{In} H_{t}-\operatorname{In} L_{t}\right)^{2}}{4 \operatorname{In} 2},
$$

where $H_{t}$ denotes the highest price of the day and $L_{t}$ denotes the lowest price of the day. The G/K estimator is an extension of the $\mathrm{H} / \mathrm{L}$ estimator and uses opening price and closing price as well as the high and low prices to estimate daily volatility:

$$
\widehat{\sigma}_{t}^{2}=0.5\left(\operatorname{In} \frac{H_{t}}{L_{t}}\right)^{2}-0.39\left(\operatorname{In} \frac{p_{t}}{p_{t-1}}\right)^{2}
$$

where $p_{t}$ is the closing price of the day and $p_{t-1}$ is the opening price of the day. For all the price measures for both estimators, we use USD denominated fixed-float swap prices with 10-year tenor from Bloomberg, and Figure 4 shows that these two estimators result in very similar daily volatility measures. We also use the Eurodollar futures from Bloomberg to represent the LIBOR rate and use the same methodology to estimate its volatility. The summary statistics of all the variables used in our empirical analysis are provided in Table 3.

\section{Empirical Results}

In this section, we use a unique interest rate swap transaction dataset with the counterparty details acquired from the SDRs to try to understand the interrelationship between swap market complexity and its impact on market volatility. We are particularly interested in the IRS market network structural features, and we aim to unravel risk-sharing behaviors of the market participants as a result of the endogeneity of the market volatility and the contract flow complexity.

4.1. Network's Topological Structure. The degree of a node in a network is the number of edges it has towards other nodes. A network is called scale-free if the distribution of degree is drawn from a power-law statistical distribution. A network
TABLE 4: Summary statistics of network centrality measures (average of all the daily swap networks).

\begin{tabular}{lcccc}
\hline & $\begin{array}{c}\text { Degree } \\
\text { centrality }\end{array}$ & $\begin{array}{c}\text { Betweenness of } \\
\text { centrality }\end{array}$ & $\begin{array}{c}\text { Closeness } \\
\text { centrality }\end{array}$ & $\begin{array}{c}\text { Eigenvector } \\
\text { centrality }\end{array}$ \\
\hline Min & 11.125 & 153.5 & 153.5084 & 0.009144 \\
Mean & 12.277 & 212.4 & 211.9831 & 0.017789 \\
Median & 12.019 & 202.9 & 202.8839 & 0.011313 \\
Max & 94.866 & 1045.8 & 1045.8166 & 0.482834 \\
\hline
\end{tabular}

Notes: this table shows the network centrality measures generated from the unweighted daily interest rate swap networks.

is called scale-free if the probability that a node selected uniformly at random has a certain number of links (degree) follows the following power-law distribution (see (10)):

$$
P(x) \propto x^{-\gamma}
$$

The power law implies that the degree distribution of these networks has no characteristic scale. In a network with a scale-free degree distribution, some vertices have a degree that is orders of magnitude larger than the average-these vertices are often called "hubs," although this is a bit misleading as there is no inherent threshold above which a node can be viewed as a hub.

Some networks with a power-law degree distribution (and specific other types of structure) can be highly resistant to the random deletion of vertices, i.e., the vast majority of vertices remain connected together in a giant component [29]. Such networks can also be quite sensitive to targeted attacks aimed at fracturing the network quickly. We observe an average degree of these daily swap networks with 12.277 (see Table 4) which is similar to what was observed in German bank lending networks Anand et al. [30]. However, the average maximum degree is about 94.866 , which is relatively high. With the power-law distribution, it indicates that a very few powerful nodes within the network attract the majority of the contract flows. Such a highly skewed distribution can be observed from several centrality measures, such as betweenness centrality, closeness centrality, and eigenvector centrality (see Table 4). 

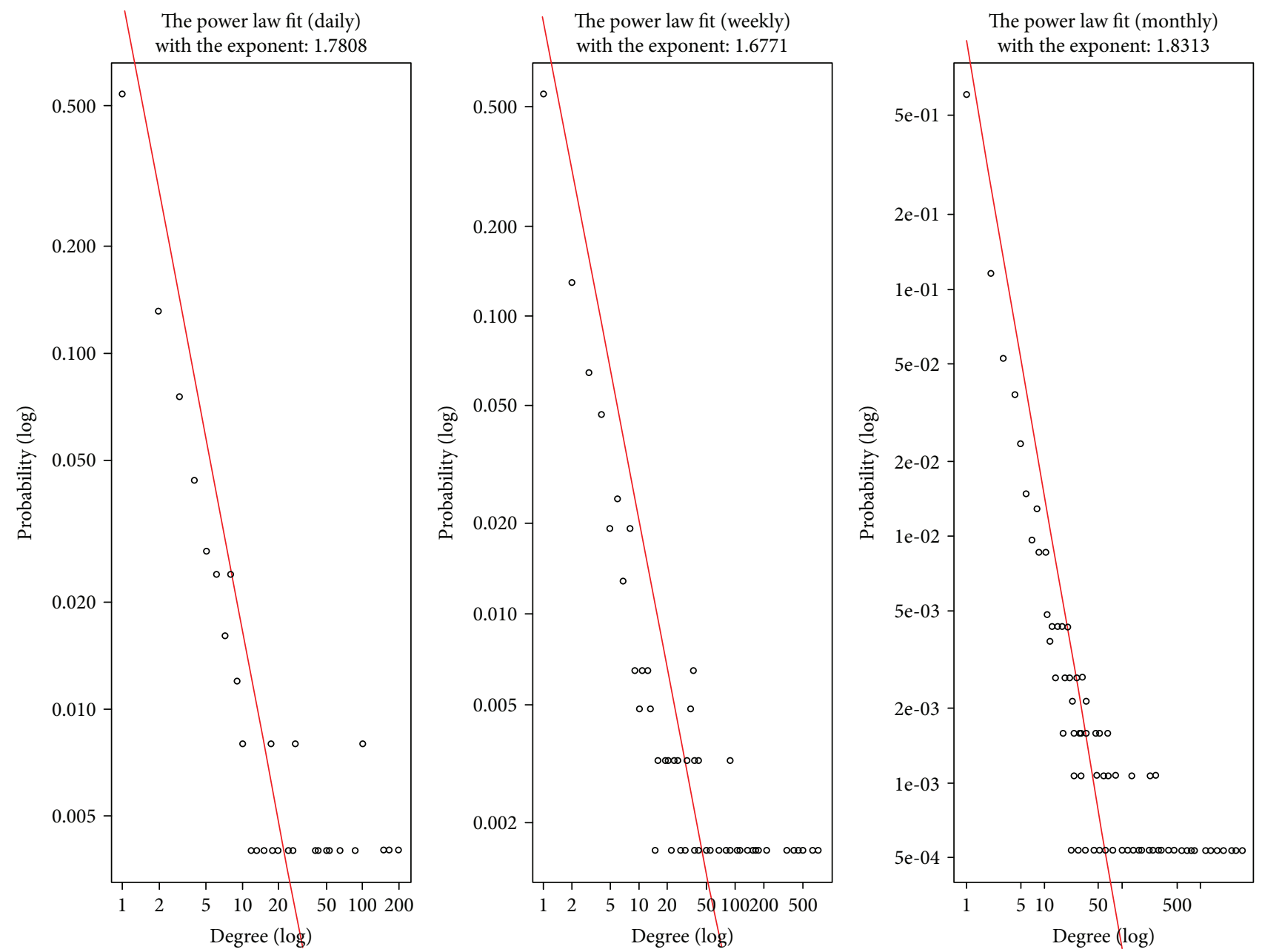

FIGURE 5: Estimates of exponents of power-law distributions. Exponents are estimated from the daily swap network reflecting contracts involving all swap users.

We test the distribution of in/out-degrees for the probability that it was drawn from a power-law statistical distribution with the Kolmogorov-Smirnov test for goodness of fit. The $p$ value resulting from this test is an approximation of the probability that the distribution of in/out-degrees fits a power-law distribution at least as well as an equivalent random sample drawn from a true power-law distribution. In computing the degree of a node, we ignore the weights on edges connected to a node. In our IRS network, the weight on an edge represents the notional value in or from a swap user. In Figure 5, we show power-law fit over time. We observe that as the number of observations increases, the statistic fit test becomes significant $(p$ value $<0.05$ ) and the power-law exponent stays in the same range, indicating consistent nonhomogeneity.

The global clustering coefficient (this measure is based on the measure of triplets of nodes. A triplet consists of three nodes that are connected by either two (open triplet) or three (closed triplet) undirected ties. A triangle consists of three closed triplets, one centered on each of the nodes. The global clustering coefficient is the number of closed triplets (or $3 \mathrm{x}$ triangles) over the total number of triplets (both open and closed)). The first attempt to measure it was made by Luce and Perry [31]) gives an indication of the clustering in the whole network (global) and can be applied to both undirected and directed networks-often called transitivity [32]. For the interest rate swap contract network, we observe an average clustering coefficient of 0.285 (see Table 5), similar to German bank lending networks [30].

The average path, the average number of steps along the shortest paths for all possible pairs of network nodes, measures how efficient payers are at finding receivers through the swap network. Empirical studies find that the average path in interbank lending networks is between 2 and 3 in length [18], [21]. We observe that, in the interest rate swap market, the average shortest path between the swap dealers is a little above 3 (see Table 5).

Now, we want to interpret the overall interest rate market structural properties. From the power-law fit, we can conclude that the swap network is a type of scale-free network which can be characterized by a highly heterogeneous degree distribution and it follows a "power law" [33]. They are called scale-free, because zooming in on any part of the distribution does not change its shape. As we examine the networks generated from the daily, weekly, and monthly data, we find they all have a similar power fit. From Figure 6, we can see that 
TABLE 5: Summary statistics of network properties (average of daily swap networks).

\begin{tabular}{lccccc}
\hline & Number of contracts & Number of entities & Clustering coefficient & Power-law exponent & Average path \\
\hline Min & 1077 & 198 & 0.080 & 1.671 & 1.807 \\
Mean & 1549 & 248 & 0.285 & 1.787 & 3.457 \\
Median & 1428 & 242 & 0.292 & 0.57 & 3.292 \\
Max & 8064 & 1576 & 0.555 & 4.089 \\
\hline
\end{tabular}

Notes: this table shows the network properties generated from the unweighted daily interest rate swap networks.

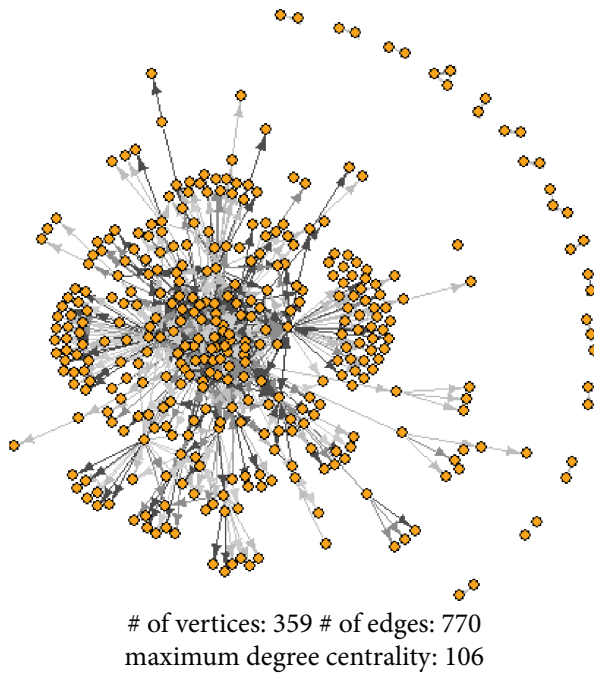

(a) A directed network with all swap entities

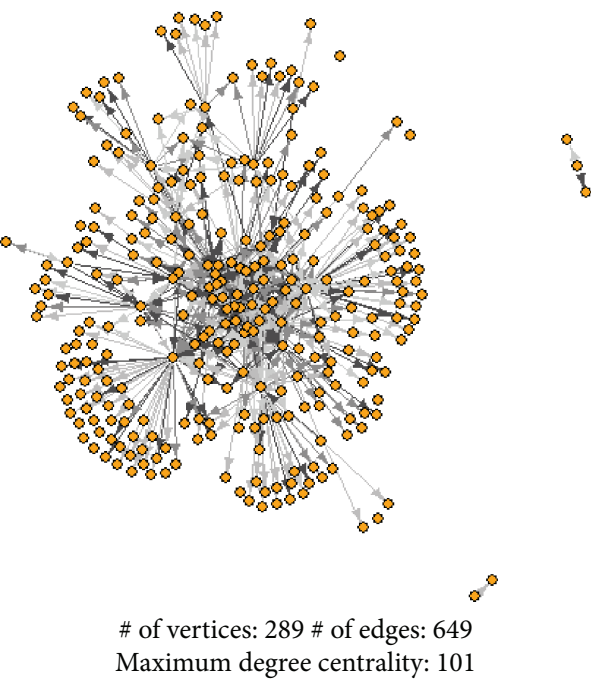

(b) A directed network with swap dealers and their counterparties

Figure 6: Swap daily network topological structures. Note: the gray scale of the arrows indicates the different levels of total notional value aggregated on a daily basis: the darker the gray, the higher the total notional value of the contracts.

there are a few, but significant, number of nodes with a lot of connections and a trailing tail of nodes with a very few connections at each level of magnification. Furthermore, it is reasonable to say that banks have preferential behavior when they choose counterparties. Barabási and Albert [33] note that growth and preferential attachment are two key factors to generating a scale-free network. We observe both factors in the interest rate swap networks. In addition, they also point out that most of the known scale-free networks have $2<\gamma<3$. If we observe a network with $\gamma<2$, it means that the fraction of links connected to the largest hub grows faster than the size of the network. This implies that for sufficiently large $N$, the degree of the largest hub (swap dealers) must exceed the total number of nodes in the network, running out of nodes to connect to. In another word, these large hubs have significant number of links pointing to themselves which in the swap market, we call them interaffiliated contracts. Because we use LEI or other unique identifier in our dataset, these self-referenced contracts are the aggregated contracts between their subsidiaries. Although the current literature [7, 17] on CDS market network structures has pointed out the scale-free network structures, this scale-free network with significant number of self-links is a new discovery that is unique to the IRS market.

From Table 4, we can interpret that there are powerful nodes of the swap networks in two different ways (see
Figure 6 for a visual interpretation). First, we observe that there are a few nodes in the network with a maximum number of contracts that are 8 times of that of the regular participants. They constitute the "too-big-to-fail" institutions in the IRS market. At the same time, we look at the betweenness centrality and eigenvector centrality, two of the influence and interconnected measures, and find that there is a small group of institutions (indicated by the maximum values) who are tightly connected with a much larger influence than the regular market participants. We may define them as "too-interconnected-to-fail" institutions. We find that these two groups have great overlap based on their user type classification information. In other words, there exists a set of institutions who are both very big in terms of IRS positions and interconnectedness with the rest of the network. Failure of any one of these institutions will have significant implications on the market structure or complexity.

With weighted network constructs, we argue the $A M I$ and $H_{C}$ complexity measures capture the influence of most of characteristics of the swap market network structures. From the summary statistics of the network complexity measures (see Table 3), the total complexity represented by MacArthur complexity measure largely consists $H_{C}$ complexity (96\%) when it is further decomposed. In Table 6, we perform a set of regression analyses to show the proposed complexity measures can capture the features represented 


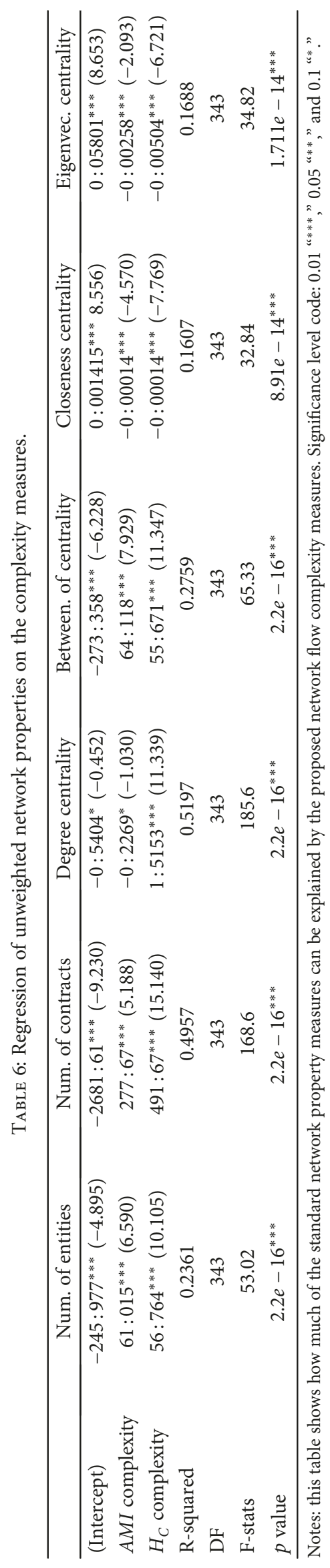


TABLE 7: Regression of swap rate volatility on network property measures (average of all the daily swap networks).

\begin{tabular}{|c|c|c|c|c|}
\hline \multirow[b]{2}{*}{ (Intercept) } & \multicolumn{2}{|c|}{$\mathrm{H} / \mathrm{L}$ swap rate volatility } & \multicolumn{2}{|c|}{ G/K swap rate volatility } \\
\hline & $2.128 e-04^{* *}(2.424)$ & $-3.430 e-04^{* *}(-2.305)$ & $5.556 e-04^{* *}(2.253)$ & $-9.705 e-04^{* *}(-2.305)$ \\
\hline Num. of entities & $-3.269 e-07(-0.615)$ & & $-3.269 e-07(-0.755)$ & \\
\hline Num. of contracts & $1.491 e-07^{* * *}(2.443)$ & & $4.209 e-07^{* * *}(2.454)$ & \\
\hline Degree centrality & $-7.864 e-06(-1.431)$ & & $-2.322 e-05(-1.503)$ & \\
\hline Betweenness centrality & $5.821 e-07(1.054)$ & & $2.129 e-06(1.371)$ & \\
\hline Closeness centrality & $-2.441 e-02(-0.492)$ & & $-6.918 e-02(-0.496)$ & \\
\hline Eigenvector centrality & $1.313 e-04(0.082)$ & & $5.370 e-04(0.119)$ & \\
\hline AIM complexity & & $1.138 e-04^{* * *}(3.914)$ & & $3.203 e-04^{* * *}(3.894)$ \\
\hline$H_{C}$ complexity & & $8.299 e-05^{* * *}(4.908)$ & & $2.342 e-04^{* * *}(4.897)$ \\
\hline R-squared & 0.09731 & 0.06467 & 0.1088 & 0.06432 \\
\hline $\mathrm{DF}$ & 343 & 343 & 343 & 343 \\
\hline F-statistics & 6.45 & 12.55 & 7.306 & 12.48 \\
\hline$p$ value & $1.797 e-06^{* * *}$ & $5.376 e-06^{* * *}$ & $2.218 e-07^{* * *}$ & $5.746 e-06^{* * *}$ \\
\hline
\end{tabular}

Notes: this table compares the regression results of IRS market volatility on network centrality measures and the network complexity measures. Significance level code: 0.01 “***," 0.05 “**," and 0.1 “*."

by the traditional network structural property measures. From these results, we see that the combination of the global diversification complexity and the local intensity complexity explains 50\% and 52\% (measure in R-squared value in the linear regression) of the variation in the number of contracts and the average degree centrality of the swap market. These two measures also capture $24 \%$ of variation of the number of participants. They also provide significant explanation to the three key network structure measures, namely, the betweenness centrality (27\% R-squared value), the closeness centrality (16\% R-squared value), and the eigenvector centrality (17\% R-squared value). When we perform joint regression analysis toward the market volatility, we find none of the unweighted centrality measures gives significant explanatory power. Moreover, when we perform a set of regressions using both the complexity measures and the traditional network measures, we find the two complexity measures of the weighted network has a significant relationship with the swap market volatility (see Table 7). But when we use the traditional network measures to explain the swap market volatility, we find only the number of contracts is significant. All other important network structure measures are not significant. As shown from the third columns in Table 6, we can see there is a strong relationship between the number of contracts and the two complexity measures, which means the two complexity measures can explain most of the contract number changes. All these analyses point out that the two proposed complexity measures are effective in explaining the swap market volatility. We further examine the dynamic relationships between the market volatility and the complexity measures in details in the next section.

4.2. Complexity Vs. Interest Rate Risk Analysis. In this section, we aim to examine the relationships between the proposed network complexity measures and the various interest rate risk measures. Our goal is to understand whether there exists a causal relationship between the interest rate risk and the swap rate risk. And we also want to understand whether there is causal relationships between the proposed network complexity measures and the interest rate risk measures. In this study, we use the two realized volatility estimators, i.e., $\mathrm{H} / \mathrm{L}$ and $\mathrm{G} / \mathrm{K}$, to represent risks. Besides our swap market volatility measures, we also focus on Eurodollar futures volatility measure since both instruments are priced based on the same underlying rate, LIBOR. Eurodollar futures and interest rate swaps are (almost) fungible derivatives ([8] states that interest rate swap valuations based on replicating portfolios of consecutive threemonth Eurodollar futures contracts perform relatively well) and that makes them a compatible pair where market participants might want to lay off their risk in one market with exposure in the other (for more on Eurodollar futures and how they are intertwined with interest rate swaps, see https://www.cmegroup.com/trading/interestrates/files/understanding-eurodollar-futures.pdf).

First, we want to look at the pairwise correlations between the swap market complexity measures and the interest rate related risk measures that we use in this study. Table 8 shows Pearson correlation tests among these variables. From these results, we observe that the MacArthur complexity has $81 \%$ positive correlation with the $H_{C}$ complexity, and the $H_{C}$ complexity have $77 \%$ significant negative correlation with $A M I$ complexity. The AMI complexity measure has no significant correlation with the swap rate volatility but has significant negative correlation with the interest rate volatility (represented by Eurodollar futures volatility). However, the $H_{C}$ complexity has significant correlation with both the swap rate volatility and the Eurodollar futures volatility. At the same time, we also observe 17\%-18\% correlation between the Eurodollar futures volatility and the swap rate volatility. In the remaining of the section, we further explore the lagged relationships of these significant correlation pairs in the form of Granger causality test.

Prior to the time series Granger causality analysis, we need to perform stationarity tests for time series using the 
TABLE 8: Pearson correlation tests for the complexity measures and volatility of Eurodollar futures and swap rates.

\begin{tabular}{|c|c|c|c|c|c|c|}
\hline Variables & [2] & [3] & {$[4]$} & [5] & [6] & [7] \\
\hline [1] MacArthur complexity & $-0.26^{* * *}$ & $0.81^{* * *}$ & $0.21^{* * *}$ & $0.21^{* * *}$ & $0.18^{* * *}$ & $0.16^{* * *}$ \\
\hline [2] AMI complexity & $1.00^{* * *}$ & $-0.77^{* * *}$ & 0.01 & 0.01 & $-0.18^{* * *}$ & $-0.17^{* * *}$ \\
\hline [3] $H_{C}$ complexity & & $1.00^{* * *}$ & $0.13^{* * *}$ & $0.13^{* * *}$ & $0.23^{* * *}$ & $0.21^{* * *}$ \\
\hline [4] Swap (1-year) rate H/L volatility & & & $1.00^{* * *}$ & $0.98^{* * *}$ & $0.18^{* * *}$ & $0.17^{* *}$ \\
\hline [5] Swap (1-year) rate G/K volatility & & & & $1.00^{* * *}$ & $0.18^{* * *}$ & $0.17^{* *}$ \\
\hline [6] Eurodollar futures $\mathrm{H} / \mathrm{L}$ volatility & & & & & $1.00^{* * *}$ & $0.98^{* * *}$ \\
\hline [7] Eurodollar futures $\mathrm{G} / \mathrm{K}$ volatility & & & & & & $1.00^{* * *}$ \\
\hline
\end{tabular}

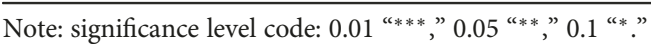

TABLE 9: The results of the Augmented Dickey Fuller (ADF) test for a unit root.

\begin{tabular}{|c|c|c|c|c|c|c|}
\hline Time series & ADF test statistics & $99 \%$ critical value & $90 \%$ critical value & $90 \%$ critical value & Lag order & $p$ value \\
\hline MacArthur complexity & -7.052 & -3.98 & -3.42 & -3.13 & 4 & $<0.0001^{* * *}$ \\
\hline$A M I$ complexity & -8.236 & -3.98 & -3.42 & -3.13 & 4 & $<0.0001^{* * *}$ \\
\hline$H_{C}$ complexity & -6.516 & -3.98 & -3.42 & -3.13 & 4 & $<0.0001^{* * *}$ \\
\hline Swap (1-year) rate $\mathrm{H} / \mathrm{L}$ volatility & -6.386 & -3.98 & -3.42 & -3.13 & 4 & $<0.001^{* * *}$ \\
\hline Swap (1-year) rate $\mathrm{G} / \mathrm{K}$ volatility & -6.386 & -3.44 & -2.87 & -2.57 & 4 & $<0.001^{* * *}$ \\
\hline Eurodollar H/L volatility & -7.378 & -3.98 & -3.42 & -3.13 & 4 & $<0.001^{* * *}$ \\
\hline Eurodollar $\mathrm{G} / \mathrm{K}$ volatility & -7.420 & -3.98 & -3.42 & -3.13 & 4 & $<0.001^{* * *}$ \\
\hline
\end{tabular}

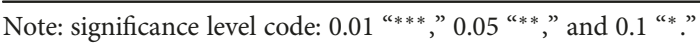

TABLE 10: The results of the bivariate Granger causality test for Eurodollar futures volatility and interest rate swap volatility.

\begin{tabular}{|c|c|c|c|}
\hline Null hypothesis & F-stats & Lag order & $p$ value \\
\hline Eurodollar futures vol. does not Granger-cause HnL swap rate vol. & 0.927 & 3 & 0.427 \\
\hline HnL swap rate vol. does not Granger-cause Eurodollar futures vol. & 1.037 & 3 & 0.375 \\
\hline Eurodollar futures vol. does not Granger-cause GnK swap rate vol. & 0.688 & 3 & 0.559 \\
\hline GnK swap rate vol. does not Granger-cause Eurodollar futures vol. & 1.064 & 3 & 0.364 \\
\hline
\end{tabular}

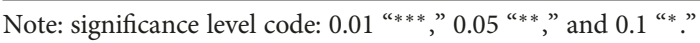

Augmented Dickey Fuller (ADF) test. For each of our variables, the hypothesis of nonstationarity can be rejected at the 0.05 confidence level. If the time series of levels cannot be assumed to be stationary, we calculate the differentiated time series and perform the ADF test on the time series of difference. The results of ADF tests are summarized in Table 9. The three complexity measures along with the Eurodollar futures and the swap rate volatility measures are all stationary at the ordinary level I (1) (see Table 9).

The significance of the relationships between variables serve as a multidimensional extension of Granger causality test. The complexity of swap network $C_{t}$ is said to Grangercause swap rate volatility $V_{t}$ if it can be shown that the values of $C_{t}$ provide statistically significant information about the future values of $V_{t}$. We conduct the bidirectional Granger causality test for all pairs between the network complexity measures and the volatility variables. In Tables 10, 11, and 12 , the test hypotheses and the results of the bivariate Granger causality tests are presented. Overall, we find that there is no Granger causal relationship between the interest rate volatility and the swap rate volatility (see Table 10). There is only a contemporary correlation between these rate volatility measures. Furthermore, we find no Granger causal relationship between either the global diversification $A M I$ and the swap rate volatility or vice versa, but both the total complexity MacArthur measure and the local intensity complexity measure $H_{C}$ Granger-causes the swap rate volatility (see Table 11). We also find that there is no Granger causal relationship between the swap market complexity (neither $H_{C}$ nor $A M I$ ) and interest rate (represented by the Eurodollar futures) volatility (see Table 12). We will further interpret the influence of the MacArthur complexity and $H_{C}$ complexity on the swap rate volatility through the analysis of a vector autoregressive (VAR) model in the next section.

4.3. Vector Autoregressive Model Estimation. In this section, we use the data to estimate the vector autoregression models for the combination of the two different volatility measures 
TABLE 11: The results of the bivariate Granger causality test for each pair of the swap rate volatility and complexity.

\begin{tabular}{|c|c|c|c|}
\hline Null hypothesis & F-stats & Lag order & $p$ value \\
\hline MacArthur complex. doesn't Granger-cause HnL swap rate vol. & 0.128 & 3 & 0.943 \\
\hline HnL swap rate vol. does not Granger-cause MacArthur complex. & 2.452 & 3 & $0.062^{*}$ \\
\hline MacArthur complex. doesn't Granger-cause GnK swap rate vol. & 0.198 & 3 & 0.898 \\
\hline GnK swap rate vol. does not Granger-cause MacArthur complex. & 2.389 & 3 & $0.068^{*}$ \\
\hline AMI complexity does not Granger-cause HnL swap rate vol. & 0.298 & 3 & 0.827 \\
\hline HnL swap rate vol. does not Granger-cause AIM complexity & 0.914 & 3 & 0.434 \\
\hline AMI complexity does not Granger-cause GnK swap rate vol. & 0.366 & 3 & 0.777 \\
\hline GnK swap rate vol. does not Granger-cause $A I M$ complexity & 0.934 & 3 & 0.424 \\
\hline$H_{C}$ complexity does not Granger-cause HnL swap rate vol. & 0.278 & 3 & 0.841 \\
\hline HnL swap rate vol. does not Granger-cause $H C$ complexity & 3.215 & 3 & $0.022^{* *}$ \\
\hline HC complexity does not Granger-cause GnK swap rate vol. & 0.302 & 3 & 0.824 \\
\hline GnK swap rate vol. does not Granger-cause $H C$ complexity & 3.170 & 3 & $0.023^{* *}$ \\
\hline
\end{tabular}

Note: significance level code: 0.01 “***,” 0.05 “**,” 0.1 “*.”

TABLE 12: The results of the bivariate Granger causality test for each pair of the Eurodollar futures volatility and complexity.

\begin{tabular}{|c|c|c|c|}
\hline Null hypothesis & F-stats & Lag order & $p$ value \\
\hline MacArthur complex. doesn't Granger-cause $\mathrm{H} \backslash$ Eurodollar futures vol. & 1.604 & 3 & 0.187 \\
\hline $\mathrm{H} \backslash$ Eurodollar futures vol. does not Granger-cause MacArthur complex. & 0.483 & 3 & 0.694 \\
\hline MacArthur complex. doesn't Granger-cause GnK Eurodollar futures vol. & 1.522 & 3 & 0.208 \\
\hline GnK Eurodollar futures vol. does not Granger-cause MacArthur complex. & 0.584 & 3 & 0.626 \\
\hline$A M I$ complexity does not Granger-cause $\mathrm{H} \backslash \mathrm{L}$ Eurodollar futures vol. & 0.381 & 3 & 0.766 \\
\hline $\mathrm{H} \backslash \mathrm{L}$ Eurodollar futures vol. does not Granger-cause $A M I$ complexity & 0.186 & 3 & 0.906 \\
\hline$H C$ complexity does not Granger-cause $\mathrm{H} \backslash \mathrm{L}$ Eurodollar futures vol. & 0.961 & 3 & 0.410 \\
\hline $\mathrm{H} \backslash \mathrm{L}$ Eurodollar futures vol. does not Granger-cause $H C$ complexity & 0.449 & 3 & 0.718 \\
\hline AMI complexity does not Granger-cause GnK Eurodollar futures vol. & 0.303 & 3 & 0.823 \\
\hline GnK Eurodollar futures vol. does not Granger-cause $A M I$ complexity & 0.523 & 3 & 0.667 \\
\hline HC complexity does not Granger-cause GnK Eurodollar futures vol. & 0.939 & 3 & 0.421 \\
\hline GnK Eurodollar futures vol. does not Granger-cause $H C$ complexity & 0.785 & 3 & 0.503 \\
\hline
\end{tabular}

Note: significance level code: 0.01 “***,” 0.05 “**,” and 0.1 “*.”

and the MacArthur and $H_{C}$ complexity measures for the entire swap network. To check for the adequacy of the estimated vector autoregression models, vector autoregression lag order selection criteria are used to choose the appropriate model orders. We employ Akaike information criteria (AIC) and we find lag order 3 yields the minimum AIC value for each combination of volatility variable and complexity measure. After choosing the lag order to define the VAR model, we estimate all combinations of market variable and complexity.

In Tables 13 and 14, we list the estimated coefficients of the VAR model for a pair of volatility and $H_{C}$ complexity measure. We see that both VAR models are statistically significant with 3 lags of the two variables.

We then perform an impulse response simulation to further analyze the model effect between the swap network complexity and the market volatility. Figure 7 shows the impulse response simulation of a VAR model with the $H_{C}$ complexity and $\mathrm{H} / \mathrm{L}$ swap rate volatility. As shown in the Granger causality tests in Table 11 , both the MacArthur and $H_{C}$ complexity measures have significant influence on the swap rate volatility. The $C_{t}$ equations in Tables 13 and 14 shows significant lag-1 volatility influence other than lag-1 autocorrelation effects. But when we look at the $V_{t}$ equations presented in Tables 13 and 14, we see that the volatility only has significant response to the lagged volatility. In other words, $H_{C}$ complexity does not have an effect on market volatility, which is consistent with our Granger causality test results (see Table 11). The response is primarily due to autocorrelation effect. Figure 8 shows a very similar interaction between $H_{C}$ complexity and $\mathrm{G} / \mathrm{K}$ swap rate volatility.

4.4. Analysis and Discussions. As we can see from the earlier discussions of the complexity measures, the overall complexity increase means the increase of either the effective number of roles (the global diversification) or the effective connectivity (the local intensity) of all the nodes. From Tables 13 and 14 , we see that the total system complexity measured in MacArthur complexity can be mostly explained by $H_{C}$ complexity. It is not a surprising result from the $81 \%$ correlation 
TABLE 13: The results of swap rate volatility H/L VAR model estimation.

\begin{tabular}{lcccc}
\hline \multirow{2}{*}{ Variables } & \multicolumn{2}{c}{$C_{t}$ equation estimation results } & \multicolumn{2}{c}{$V_{t}$ equation estimation results } \\
& $H_{C}$ complexity & MacArthur complexity & $H_{C}$ complexity & MacArthur complexity \\
\hline Const & $7.562 e+00^{* * *}(10.729)$ & $5.642 e+00^{* * *}(8.964)$ & $1.931 e-04(0.921)$ & $1.359 e-04(0.444)$ \\
Trend & $3.133 e-03^{* * *}(3.493)$ & $2.184 e-03^{* * *}(4.358)$ & $-1.997 e-08(-0.087)$ & $-4.042 e-08(-0.246)$ \\
$C_{t-1}$ & $1.159 e-01^{* *}(2.114)$ & $2.227 e-01^{* *}(4.017)$ & $-5.534 e-06(-0.339)$ & $-2.379 e-07(-0.009)$ \\
$V_{t-1}$ & $5.565 e+01^{* * *}(3.044 .100)$ & $3.235 e+02(2.857)$ & $2.699 e-01^{* * *}(4.964)$ & $2.685 e-01^{* * *}(4.880)$ \\
$C_{t-2}$ & $-3.184 e-01(-0.572)$ & $8.478 e-02^{*}(1.498)$ & $-1.141 e-06(-0.069)$ & $-2.836 e-06(-0.103)$ \\
$V_{t-2}$ & $-2.425 e+02(-0.127)$ & $-3.714 e+01(-0.316)$ & $-1.987 e-02(-0.351)$ & $-2.316 e-02(-0.406)$ \\
$C_{t-3}$ & $-7.288 e-02^{*}(-1.334)$ & $-1.026 e-02(-0.188)$ & $1.366 e-05(0.841)$ & $1.696 e-05(0.638)$ \\
$V_{t-3}$ & $1.992 e+02(1.076)$ & $1.339 e+02(1.170)$ & $1.172 e-01^{* *}(2.129)$ & $1.158 e-01^{* *}(2.082)$ \\
Degrees of freedom & 335 & 335 & 335 & 335 \\
F-statistic & 5.551 & 12.98 & 4.776 & 4.708 \\
R-squared & 0.1039 & 0.2133 & 0.0907 & 0.071 \\
Adjusted R-squared & 0.0852 & 0.1969 & $3.892 e-05$ & 0.08957 \\
$p$ value & $1.782 e-6$ & $8.757 e-15$ & $4.677 e-05$ \\
\hline
\end{tabular}

Notes. L1 of a time series means time lag 1 and L2 means time lag 2. Significance level code: 0.01 “***,” 0.05 “**,” 0.1 and “*.”

TABLE 14: The results of swap rate volatility G/K VAR model estimation.

\begin{tabular}{lcccc}
\hline \multirow{2}{*}{ Variables } & \multicolumn{2}{c}{$C_{t}$ equation estimation results } & \multicolumn{2}{c}{$V_{t}$ equation estimation results } \\
& $H_{C}$ complexity & MacArthur complexity & $H_{C}$ complexity & MacArthur complexity \\
\hline Const & $7.553 e+00^{* * *}(10.711)$ & $5.646 e+00^{* * *}(8.959)$ & $6.230 e-04(9.339)$ & $3.961 e-04(0.459)$ \\
Trend & $3.157 e-03^{* * *}(4.067)$ & $2.201 e-03^{* * *}(4.383)$ & $-8.400 e-08(-0.129)$ & $-1.693 e-07(-0.246)$ \\
$C_{t-1}$ & $1.149 e-01^{* *}(2.096)$ & $2.224 e-01^{* * *}(4.011)$ & $-1.611 e-05(-0.350)$ & $1.507 e-05(0.198)$ \\
$V_{t-1}$ & $1.976 e+01^{* * *}(3.053)$ & $1.143 e+02^{* * *}(2.852)$ & $2.669 e-01^{* * *}(4.913)$ & $2.638 e-01^{* * *}(4.802)$ \\
$C_{t-2}$ & $-3.202 e-02(-0.575)$ & $8.232 e-02^{*}(1.455)$ & $-1.418 e-05(-0.303)$ & $-3.298 e-05(-0.425)$ \\
$V_{t-2}$ & $-3.539 e+00(-0.053)$ & $-1.075 e+01(-0.259)$ & $-5.900 e-03(-0.104)$ & $-9.550 e-03(-0.168)$ \\
$C_{t-3}$ & $-7.087 e-02^{*}(-1.297)$ & $-8.111 e-03(-0.148)$ & $3.851 e-05(0.840)$ & $5.438 e-05(0.725)$ \\
$V_{t-3}$ & $6.428 e+01(0.981)$ & $4.548 e+01(1.123)$ & $1.259 e-01^{* *}(2.289)$ & $1.238 e-01^{* *}(2.231)$ \\
Degrees of freedom & 335 & 335 & 335 & 335 \\
F-statistic & 5.551 & 12.98 & 4.9979 & 4.937 \\
R-squared & 0.1036 & 0.2134 & 0.0942 & 0.09351 \\
Adjusted R-squared & 0.085 & 0.1969 & $2.229 e-05$ & 0.07457 \\
$p$ value & $4.462 e-06$ & $8.669 e-15$ & $2.501 e-05$ \\
\hline
\end{tabular}

Notes. L1 of a time series means time lag 1 and L2 means time lag 2. Significance level code: 0.01 “***," 0.05 “**," and 0.1 “*.,

between the MacArthur complexity and the $H_{C}$ complexity shown in Table 8. As our correlation test has revealed, the global diversification complexity AIM has no significant correlation with the swap market volatility, but the local intensity complexity measure does. It means that when there is a volatility in the swap market, it is mostly manifested as the local contract flow intensity change. And banks and swap users generally would not change their risk management strategies which should be reflected in the global diversification changes. In other words, the swap rate volatility only has a significant effect at the local entity level. This increase of the total complexity comes primarily from counterparty risksharing capacity change, and it will not cause the increase or decrease of risk sharing diversification at the system level.
When we look at the interaction of the market $H_{C}$ complexity and swap rate volatility, we observe that the saturation of the network capacity seems to coincide with the market volatility reversal. From both Figures 7(b) and 8(b), we see the local intensity complexity $H_{C}$ does not have significant influence on the swap rate volatility; the changes in volatility mostly come from autocorrelation effect (see Tables 13 and 14). At the same time, the swap market volatility has significant impact on market intensity complexity $H_{C}$. The volatility increase from the previous day would cause swap users to increase their contract intensity, and this complexity change would not have impact on the market volatility as a result. It can be interpreted as the saturation of the market capacity would naturally put a break on volatility 


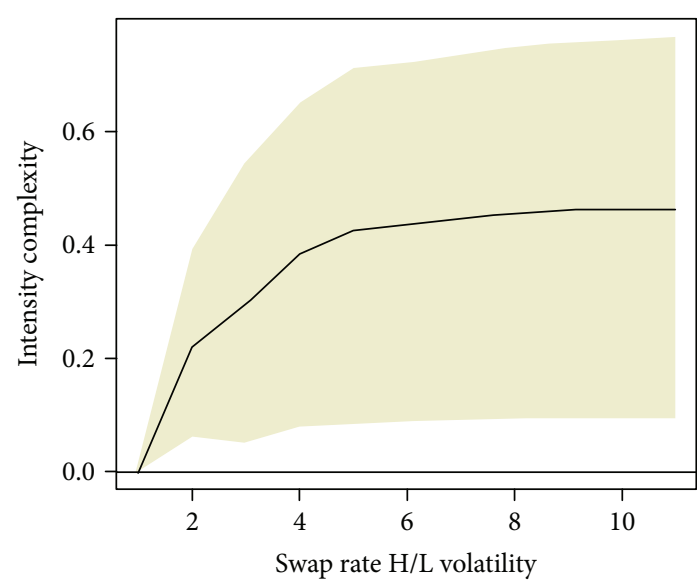

(a) $H_{C}$ complexity impulse response to $\mathrm{H} / \mathrm{L}$ swap rate volatility

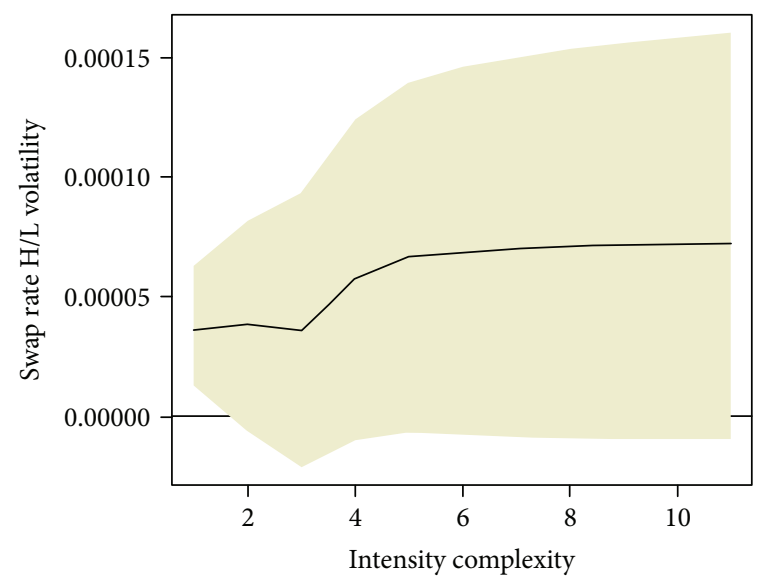

(b) $\mathrm{H} / \mathrm{L}$ swap rate volatility impulse response to $H_{C}$ complexity

Figure 7: Impulse response analysis for $H_{C}$ complexity and H/L swap rate volatility. The shaded area indicates the $95 \%$ confidence interval for simulation results. The confidence intervals get larger when they are further away from the start of the impulse.

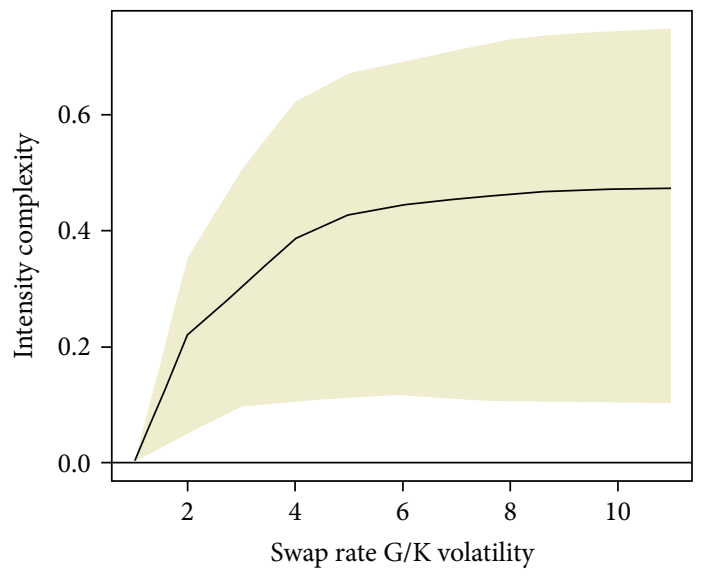

(a) $H_{C}$ complexity impulse response to $\mathrm{G} / \mathrm{K}$ swap rate volatility

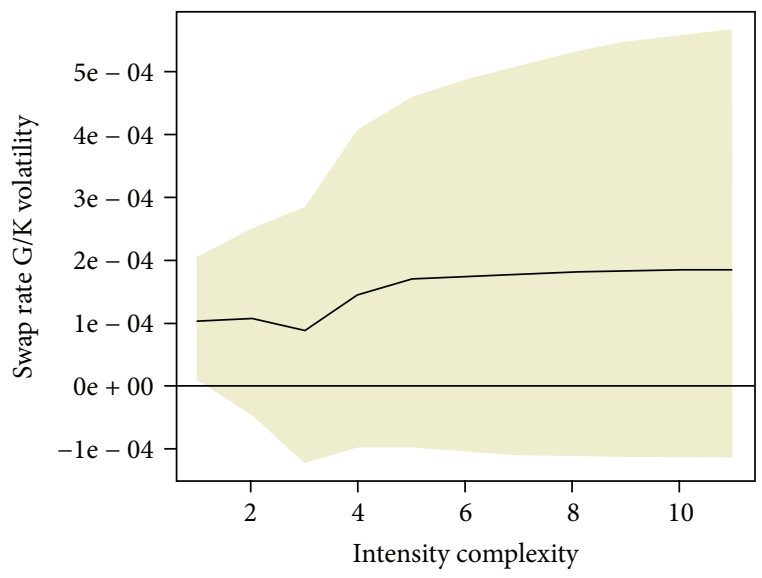

(b) G/K volatility impulse response to $H_{C}$ complexity

FIGURE 8: Impulse response analysis for $H_{C}$ complexity and G/K swap rate volatility. The shaded area indicates the $95 \%$ confidence interval for simulation results. The confidence intervals get larger when they are further away from the start of the impulse.

increase, and therefore, it prevents positive feedbacks between the complexity and volatility. From the simulation of the $H_{C}$ complexity VAR models (see Tables 13 and 14 ), we see that one unit shock in swap market volatility would cause contract flow intensity to increase in the next 3 days and then it will become stable after 6 days. Although the impulse responses after 3 days are not significantly distinguishable, the first 2 days have the steepest changes in terms of contract flow adjustments. It is reflective of the current central clearing practices. Given the central clearing requirements under the Dodd-Frank Reform Act, most of the interest rate contracts would be cleared within 2-3 days. Such volatility risk will be contained after the clearing of the swap contracts. These findings show that the post Dodd-Frank market structure helps reducing risk spread.

In addition, we check the robustness of our results with respect to both the volatility and complexity measures on dealer network which is constructed by contracts with at least one side involving a dealer. First, we perform a robustness test on complexity. As we mentioned earlier (see also Figure 6), we observe that the dealer network is representative of the entire swap network. We find that there is a $98 \%$ and $99 \%$ correlation between the $A M I$ and $H_{C}$ complexity measure of these two networks. Nevertheless, we conduct the Granger causality test and build VAR models using the entire network complexity, and we find that there is almost no change between the two networks in terms of the VAR model parameters and the impulse response simulation results. Therefore, we conclude that the model results presented in Tables 13 and 14 are representative of the entire network. It shows that the large swap participants are predominantly swap dealers, and their risk management behaviors determine the market overall outcome.

Secondly, we check the robustness of the $H_{C}$ complexity measure in our model for different swap tenors. Although we have checked models with both $\mathrm{H} / \mathrm{L}$ and $\mathrm{G} / \mathrm{K}$ volatility 
measures, we want to make sure volatility of the short-term tenor IRS market has the same effect as the long-term tenor IRS market. To answer this question, we use volatility data for the 1-year tenor IRS market and apply the same methodology to construct the short-term tenor market volatility using both the $\mathrm{H} / \mathrm{L}$ and $\mathrm{G} / \mathrm{K}$ methods. We then perform the same modeling exercise as that of the 20-year IRS market. We find again that both the $\mathrm{H} / \mathrm{L}$ and $\mathrm{G} / \mathrm{K}$ volatility measures Granger-cause the $H_{C}$ complexity to increase. We also find that, instead of up to 2 lags of significant influence of the volatility from the $H_{C}$ complexity, only 1 lag of volatility has significant influence to market complexity. In the same way, the complexity does not Granger-cause the volatility to change. The impulse response simulation results show the similar effect from the VAR model we obtained from the 20-year tenor IRS market, but the cumulative effect becomes stable faster than the 20-year IRS market. This is reasonable because the 1-year IRS market is likely to respond to the volatility faster than the 20-year IRS market. Overall, the robustness test of both variables in our modeling exercise shows consistent results.

\section{Conclusion}

This paper examines network structure of the post DoddFrank interest rate swap market and aims to bring better understanding of how the swap users respond to the interest rate risks. Utilizing a unique SDR dataset collected pursuant to the Dodd-Frank Act, we propose two weighted network complexity measures to capture the dynamic nature of the counterparty exposures of the interest rate swap market, characterized by "too big to fail" and "too interconnected to fail" institutions. We document that the interest rate swap market follows a scale-free network with a core and peripheral type of topology. Especially, we find the interest rate swap market scale-free network has a unique feature which is the large hubs of the network have a significant number of self-links, i.e., interaffiliated contracts. More importantly, we show that the two complexity measures-one explains the global risk diversification and another measures the local risk-sharing intensity-can help us to understand the swap market dynamics in terms of swap contract flow concentration and counterparty risk sharing intensity. Moreover, we find the market volatility Granger-causes the market risk-sharing intensity to increase, but the global risk diversification has no significant change at the same time. This intensity increase can be interpreted as the swap users' reaction to manage their interest rate risk by increasing their existing positions. This market force is initially amplified by the increase in complexity but then is dampened by the reversal of volatility. One possible explanation is the saturation of the contract market, meaning when firms have increased their hedging positions, it will naturally limit further increases in volatility, displaying a mean-reverting pattern. As a result, the market complexity will also naturally revert back its equilibrium state. Moreover, we also find that the swap market volatility will not change the global risk diversification, which means that interest swap market participants in general do not change their risk management strategies. This finding is significant in that it suggests that the regulators can employ the $A M I$ global diversification complexity measure to monitor market participants' risk management behavior changes and consequently understand their global implications.

In summary, our major findings are as follows. First, the interest rate swap market follows a scale-free network where the power-law exponent is less than 2, which indicates that a few of the important entities within the swap market form the core of the network and the rest are less connected. Also, the important players generate a significant number of interest rate swap contracts between their subsidiaries. Secondly, swap rate volatility Granger-causes swap users largely to increase their risk-sharing intensity at entity level, but market participants do not change their risk management strategies in general. We find adding counterparty risk-sharing capacity is the predominant response to the swap market volatility increase from the market participants. Finally, the interest rate swap volatility does not cause the underlying interest rate futures volatility and vice versa. However, there is a significant contemporaneous correlation between the swap rate volatility and the underlying interest rate volatility.

These findings would help regulators to better understand the large swap dealers' behavioral influence toward the stability or robustness of the interest rate swap market. In particular, monitoring the behaviors of the key players using the proposed complexity measures in the interest rate swap market such as their positions, and external and internal exposures, is key to understanding the market risksharing dynamics and the stability of the system. However, we are silent in interpreting how banks use Eurodollar futures and interest rate swaps to manage their risks. It will require linking banks' specific positions in both markets. This will be a future research topic to pursue. Furthermore, when there are long historical swap data accumulated, the study of swap participants' risk management strategies under different economic conditions would be of particular importance in unraveling the impact of systemic events to the largest financial market. Break-off from the normal market complexity patterns may have systemic risk implications toward the entire financial system due to the significant role that the interest rate swaps have toward the overall financial system.

\section{Appendix \\ Network Complexity Measures by Information Theory}

Information theory (IT) begins with Boltzmann's surprisal, which quantifies which is missing. Boltzmann's surprisal $(s)$ of an event is estimated from $s=-k \log (p)$, where $s$ is one's surprisal at seeing an event that occurs with probability $p$. However, Boltzmann's surprisal measures the absence not the presence of an event. For the small probability that an event occurs, the corresponding surprisal $s$ has a large magnitude, which means the event is not likely to occur. The product of the measure of presence of an event $i\left(p_{i}\right)$ by the 
magnitude of its absence $\left(s_{i}\right)$ yields a quantity that represents the indeterminacy $\left(h_{i}\right)$ of the event in question.

$$
h_{i}=-k p_{i} \log \left(p_{i}\right) \text {, where } \mathrm{k} \text { is a constant. }
$$

It is helpful to reinterpret equation $h_{i}=-k p_{i} \log \left(p_{i}\right)$ as it relates to evolutionary change and sustainability. $h_{i}$ represents the capacity for event $i$ to be a significant player in a system change or evolution. Regarding the entire ensemble of events, one can aggregate all the indeterminacies to create a metric of the total capacity of the system subject to change:

$$
H=\sum_{i} h_{i}=-k \sum_{i} p_{i} \log (p i) .
$$

MacArthur applied the above well-known Shannon's information measure [28] to the flows in an ecosystem network as an important tool to define the system diversity and stability [27] as follows:

$$
H=-k \sum_{h, j}\left(\frac{T_{h j}}{T_{. .}}\right) \log \left(\frac{T_{h j}}{T_{. .}}\right) .
$$

Later, Rutledge et al. [29] were able to decompose MacArthur's index into two complementary terms using the notion of conditional probability. Taking $\left(T_{i j} / T_{. .}\right)$as the estimate of the unconditional probability that a flow occurs from $i$ to $j,\left(T_{i j} / T_{. j}\right)$ then becomes the estimator of the conditional probability that any quantum of flow continues on to component $j$, given that it had originated from component $i$. This allows $H$ to be decomposed into two parts.

$$
H=A M I+H_{C},
$$

where $A M I=k \sum_{h, j}\left(T_{h j} / T_{. .}\right) \log \left(T_{h j} T_{. .} / T_{h .} T_{. j}\right)$ and $H_{C}=k \sum_{h, j}$ $\left(T_{h j} / T_{. .}\right) \log \left(T_{h j}^{h j} / T_{h .} T_{. j}\right)$.

The overall complexity of the flow network, as measured by MacArthur's index, can be decomposed into two parts, $A M I$ and $H_{C}$. $A M I$ is the average mutual information inherent in the flow structure, and $H_{C}$ is the conditional entropy. $A M I$ measures how orderly and coherently the flows are connected, while $H_{C}$ measures the residual diversity or potential in the network. MacArthur's index is equivalent to the logarithm of the number of flows in the weighted network. If we combine (2) and (A.3) and further introduce $R$ and $C$ from (1) and (4), we can arrive at a representation of MacArthur's entropy in terms of network flow measures. AMI and $H_{C}$ are equivalent to the logarithm of the number of roles and the connectivity, respectively.
Equation (A.5) shows the equivalence between $A M I$ and the logarithm of the number of roles and the equivalence between $H_{C}$ and the logarithm of connectivity.

$$
\begin{aligned}
H & =k \sum_{h, j}\left(\frac{T_{h j}}{T_{. .}}\right) \log \left(\frac{T_{h j} T_{. .}}{T_{h \cdot T_{. j}}}\right)+k \sum_{h, j}\left(\frac{T_{h j}}{T_{. .}}\right) \log \left(\frac{T_{h j}^{2}}{T_{h \cdot T_{\cdot j}}}\right) \\
& =k \cdot \log (R)+k \cdot \log (C) .
\end{aligned}
$$

We can further interpret (A.5) with some mathematical manipulation and substitute definition of $R$ from (1) and arrive the following:

$$
\begin{aligned}
H & =k \cdot \log (R)+k \cdot \log (C)=k \cdot \log (R \cdot C) \\
& =k \cdot \log \left(\frac{F}{C} \cdot C\right)=k \cdot \log (F) .
\end{aligned}
$$

From (A.5) and (A.6), we can see that MacArthur complexity measure is equivalent to the network flow measure $F$ we developed earlier, and such complexity consists of two components, namely, the number of roles and the connectivity of a weighted flow network. When we adopt the complexity index to measure the interest rate swap contract flows, its components describe the orderliness and freedom of the entire flow network. From this concept, we can then interpret how the evolution of the interest rate swap contract flow diversity and potential helps us to understand the market dynamics. More specifically, the complexity can be interpreted as the risk-sharing diversification at both the system level and individual level. An increase in $R$ means at the system level, the risk sharing will be more diversified, while an increase in $C$ means more entities will be directly connected on average at local level.

\section{Data Availability}

The data used to support the findings of this study are available from the corresponding author upon request.

\section{Disclosure}

An earlier version of the abstract was published on the 2017 IFABS Oxford Conference and Rensselaer Polytechnic Institute website [34]. An earlier version of the preprint, dated on July 26, 2017, is also made available on Social Science Research Network under the title "Interest Rate Swap Market Complexity and Its Volatility Implication." Note: the research presented in this paper was coauthored by Esen Onur in his official capacity as a CFTC employee and by Steve Y. Yang in his official capacity as a limited-term CFTC employee with the position title of unpaid consultant. The Office of the Chief Economist and CFTC economists produce original research on a broad range of topics relevant to the CFTC's mandate to regulate commodity futures markets, commodity options markets, and the expanded mandate to regulate the swaps markets pursuant to the Dodd-Frank Reform Act. These papers are often presented at conferences 
and many of these papers are later published by peer-review and other scholarly outlets. The analyses and conclusions expressed in this paper are those of the authors and do not reflect the views of other members of the Office of Chief Economist, the Division of Enforcement, other Commission staff, or the Commission itself. Errors and omissions, if any, are the authors' sole responsibility. Neither the funding agency nor any outside organization has participated in study design or have any competing interest.

\section{Conflicts of Interest}

The authors declare that they have no conflicts of interest.

\section{Acknowledgments}

The authors would like to thank Sriya Anbil, Mark Flood, Mark Paddrik, Sayee Srinivasan, Scott Mixon, Aparna Gupta, and Michel Robe for their valuable comments. We also thank participants of financial seminars at the 2017 IFABS Oxford Conference, Office of Financial Research, Office of Chief Economist of the Commodity Futures Trading Commission, and Rensselaer Polytechnic Institute for their valuable comments during the research seminar. The research was funded by CFTC. CFTC had final approval of the manuscript.

\section{References}

[1] D. Duffie, N. Gârleanu, and L. H. Pedersen, "Over-the-counter markets," Econometrica, vol. 73, no. 6, pp. 1815-1847, 2005.

[2] E. Benos, R. Payne, and M. Vasios, Centralized Trading, Transparency and Interest Rate Swap Market Liquidity: Evidence from the Implementation of the Dodd-Frank Act, Bank of England Working Paper, Bank of England Working Paper, 2016https://ssrn.com/abstract=2716066.

[3] A. Fulop and L. Lescourret, Transparency Regime Initiatives and Liquidity in the CDS Market, SSRN Working Papers, (284), SSRN Working Papers, (284), 2015Available at SSRN: https://ssrn.com/abstract=2551169.

[4] L. Riggs, E. Onur, D. Reiffen, and H. Zhu, Mechanism Selection and Trade Formation on Swap Execution Facilities: Evidence from Index CDS, SSRN Working Papers, SSRN Working Papers, 2017Available at SSRN: https://ssrn.com/abstract= 3047284.

[5] J. Abad, I. Aldasoro, C. Aymanns et al., "Shedding light on dark markets: first insights from the new eu-wide otc derivatives dataset," in ESRB Occasional Paper Series, 10, pp. 1-32, European Systemic Risk Board, Frankfurt, Germany, 2016.

[6] S. Markose, S. Giansante, and A. R. Shaghaghi, “Too interconnected to fail' financial network of us CDS market: topological fragility and systemic risk," Journal of Economic Behavior \& Organization, vol. 83, no. 3, pp. 627-646, 2012.

[7] T. A. Peltonen, M. Scheicher, and G. Vuillemey, "The network structure of the CDS market and Its determinants," Journal of Financial Stability, vol. 13, pp. 118-133, 2014.

[8] B. A. Minton, "An empirical examination of basic valuation models for plain vanilla U.S. interest rate swaps," Journal of Financial Economics, vol. 44, no. 2, pp. 251-277, 1997.

[9] D. Cossin and H. Pirotte, "Swap credit risk: an empirical investigation on transaction data," Journal of Banking \& Finance, vol. 21, no. 10, pp. 1351-1373, 1997.
[10] S. Balsam and S. Kim, "Effects of interest rate swaps," Journal of Economics and Business, vol. 53, no. 6, pp. 547-562, 2001.

[11] H. Li and C. X. Mao, "Corporate use of interest rate swaps: theory and evidence," Journal of Banking \& Finance, vol. 27, no. 8, pp. 1511-1538, 2003.

[12] J. T. Harper and J. R. Wingender, "An empirical test of agency cost reduction using interest rate swaps," Journal of Banking \& Finance, vol. 24, no. 9, pp. 1419-1431, 2000.

[13] A. S. M. S. Azad, V. Fang, and C.-H. Hung, "Linking the interest rate swap markets to the macroeconomic risk: the UK and US evidence," International Review of Financial Analysis, vol. 22, pp. 38-47, 2012.

[14] S. J. Byun and K. C. Chang, "Volatility risk premium in the interest rate market: evidence from delta-hedged gains on USD interest rate swaps," International Review of Financial Analysis, vol. 40, pp. 88-102, 2015.

[15] Y. C. Loon and Z. K. Zhong, "Does dodd-frank affect otc transaction costs and liquidity? Evidence from real-time cds trade reports," Journal of Financial Economics, vol. 119, no. 3, pp. 645-672, 2016.

[16] O. Kaya, CDS Spreads Widen under Central Clearing Obligation, Working Paper, Working Paper, 2013.

[17] P. Collin-Dufresne, B. Junge, and A. B. Trolle, "Market structure and transaction costs of index CDSs," in Swiss Finance Institute Research Paper No. 18-40, 2016, Available at SSRN: https://ssrn.com/abstract=2786907.

[18] M. Boss, H. Elsinger, M. Summer, and S. Thurner, "Network topology of the interbank market," Quantitative Finance, vol. 4, no. 6, pp. 677-684, 2004.

[19] G. Iori, G. De Masi, O. V. Precup, G. Gabbi, and G. Caldarelli, "A network analysis of the Italian overnight money market," Journal of Economic Dynamics and Control, vol. 32, no. 1, pp. 259-278, 2008.

[20] R. Cont, A. Moussa, and E. B. Santos, "Network structure and systemic risk in banking systems," in Network Structure and Systemic Risk in Banking Systems (December 1, 2010), 2010, Available at SSRN: https://ssrn.com/abstract $=1733528$.

[21] L. Bargigli, G. Di Iasio, L. Infante, F. Lillo, and F. Pierobon, "The multiplex structure of interbank networks," Quantitative Finance, vol. 15, no. 4, pp. 673-691, 2015.

[22] D. Acemoglu, A. Ozdaglar, and A. Tahbaz-Salehi, "Systemic risk and stability in financial networks," The American Economic Review, vol. 105, no. 2, pp. 564-608, 2015.

[23] D. J. Watts and S. H. Strogatz, "Collective dynamics of 'smallworld' networks,” Nature, vol. 393, no. 6684, pp. 440-442, 1998.

[24] R. E. Ulanowlcz and J. S. Norden, "Symmetrical overhead in flow networks," International Journal of Systems Science, vol. 21, no. 2, pp. 429-437, 1990.

[25] R. E. Ulanowicz, "Quantitative methods for ecological network analysis," Computational Biology and Chemistry, vol. 28, no. 56, pp. 321-339, 2004.

[26] R. MacArthur, "Fluctuations of animal populations and a measure of community stability," Ecology, vol. 36, no. 3, pp. 533-536, 1955.

[27] C. Shannon, "A mathematical theory of communication," Mathematical Reviews (Math Sci Net), vol. MR10, article 133e, 1948.

[28] R. W. Rutledge, B. L. Basore, and R. J. Mulholland, "Ecological stability: an information theory viewpoint," Journal of Theoretical Biology, vol. 57, no. 2, pp. 355-371, 1976. 
[29] S. A. Kauffman, "Antichaos and adaptation," Scientific American, vol. 265, no. 2, pp. 78-84, 1991.

[30] K. Anand, B. Craig, and G. von Peter, "Filling in the blanks: network structure and interbank contagion," Quantitative Finance, vol. 15, no. 4, pp. 625-636, 2015.

[31] R. D. Luce and A. D. Perry, "A method of matrix analysis of group structure," Psychometrika, vol. 14, no. 2, pp. 95-116, 1949.

[32] S. Wasserman and K. Faust, Social Network Analysis: Methods and Applications, Volume 8, Cambridge University Press, 1994.

[33] A.-L. Barabási and R. Albert, "Emergence of scaling in random networks," Science, vol. 286, no. 5439, pp. 509-512, 1999.

[34] S. Yang and E. Onur, "Interest rate swap market complexity and its risk implication," in International Finance and Banking Society Conference, 2017, Oxford, UK, 2017. 


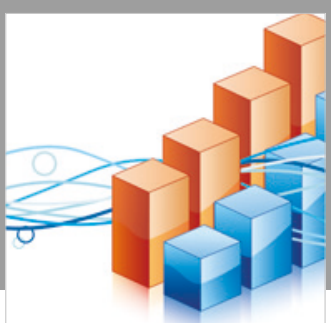

Advances in

Operations Research

\section{-n-m}
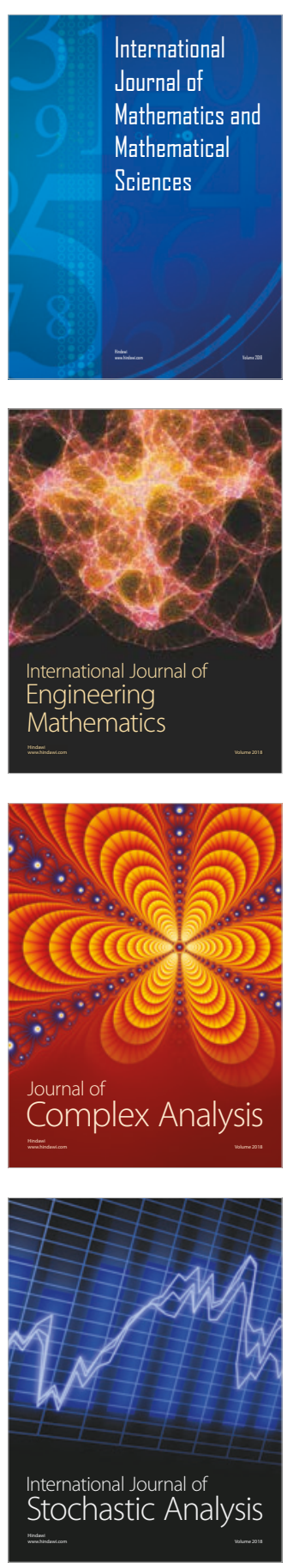
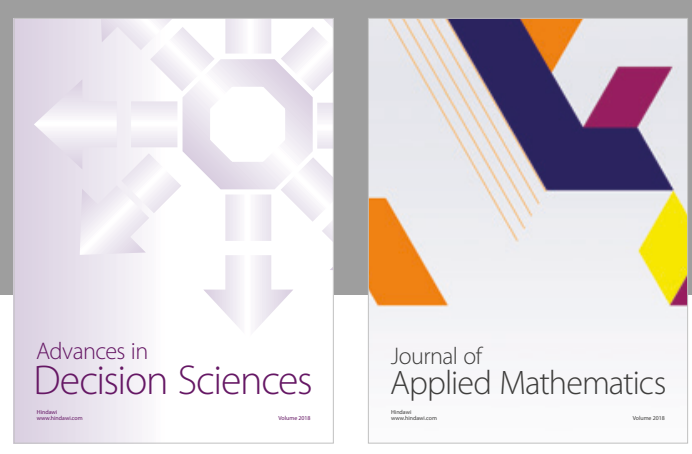

Journal of

Applied Mathematics
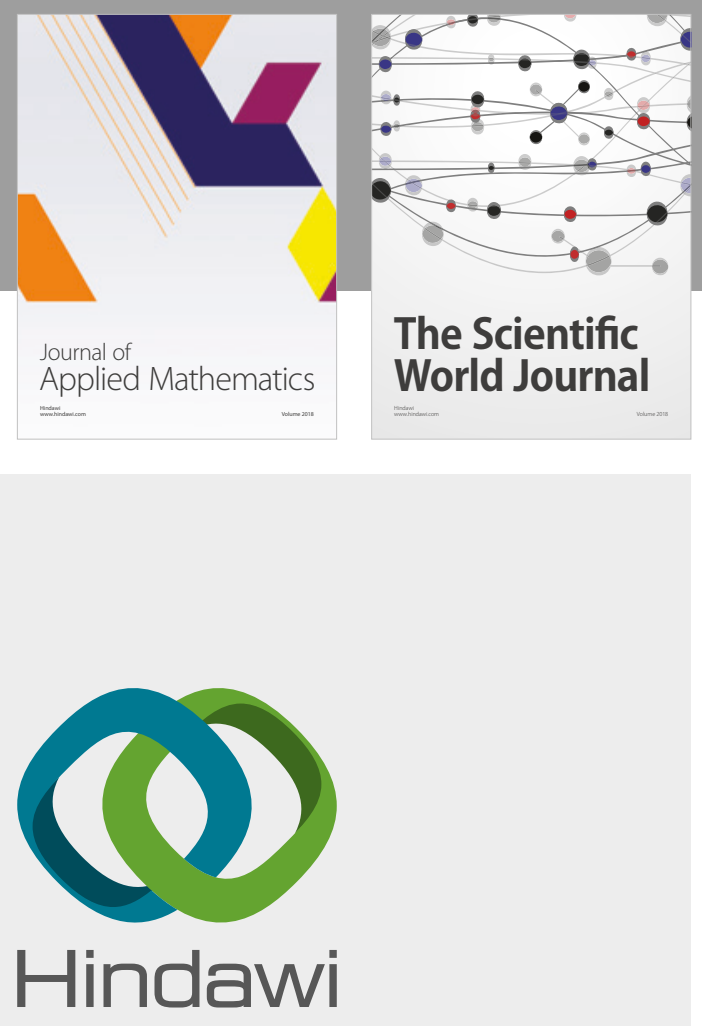

Submit your manuscripts at

www.hindawi.com

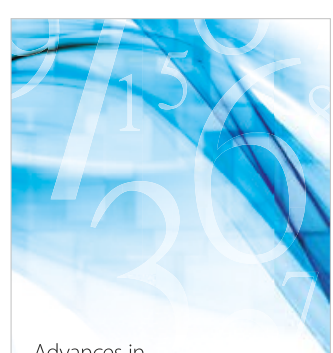

Advances in
Numerical Analysis
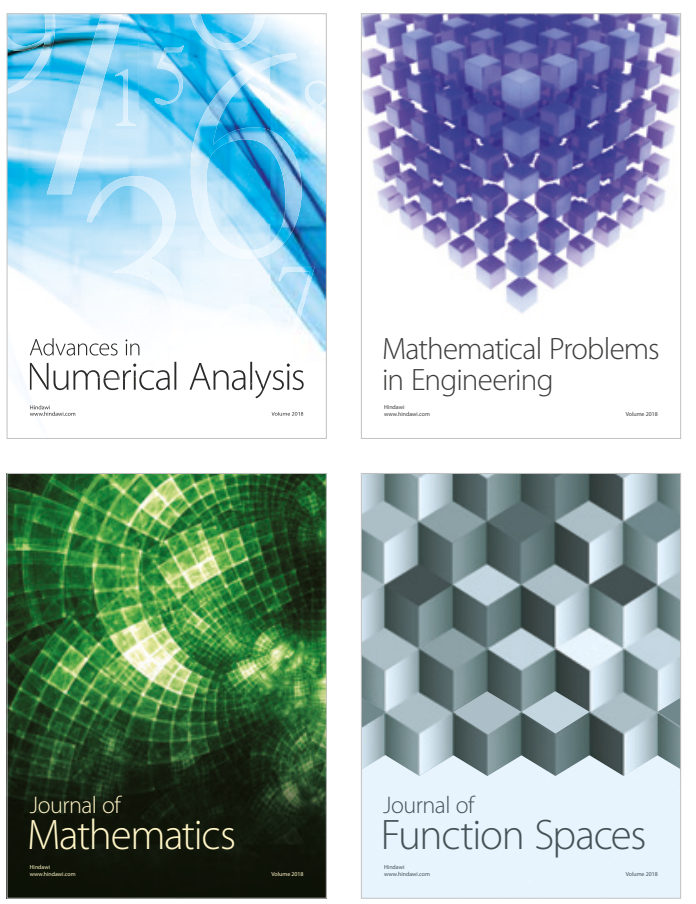

Mathematical Problems in Engineering

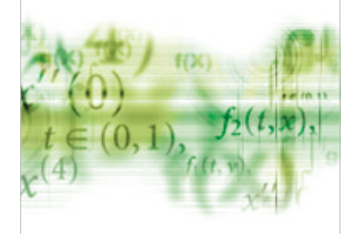

International Journal of

Differential Equations

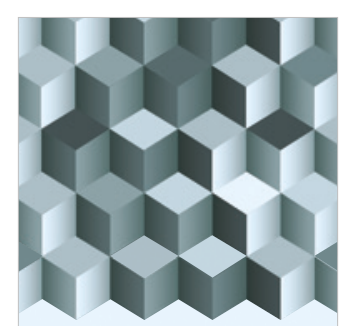

Journal of

Function Spaces
The Scientific

World Journal

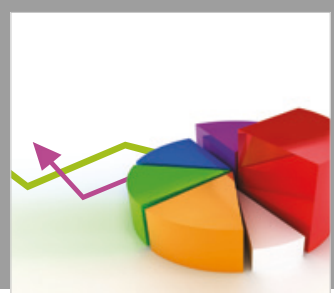

Journal of

Probability and Statistics
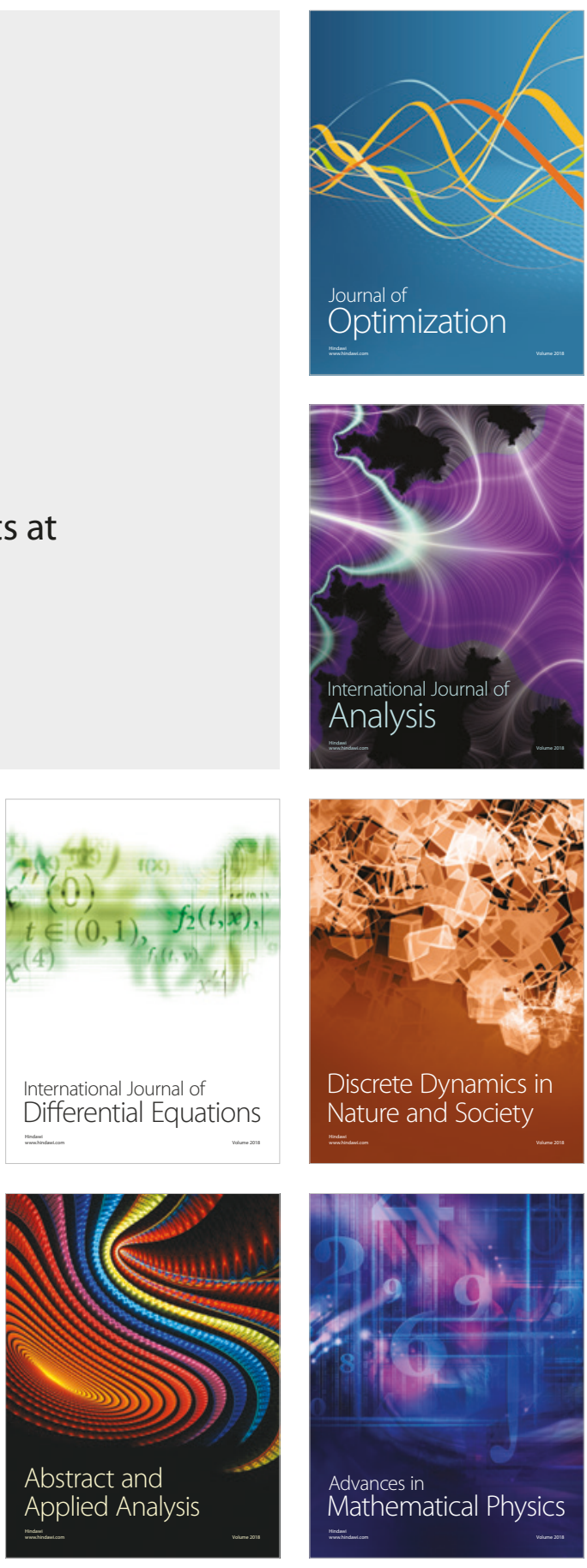